\title{
المنهج النقدى عند "جين هامتون " دراسة فى نشأة السلطة
}

د. أشرف همهود أهين حسان"'

ملفص

يدور هذا البحث حول موقف جين هامتون من نظريات نشأة السلطة فى المجتمع، فقد رفضت نظرية السلطة الإلهية فهي أشبه بالآراء الميتافيزيقية التي لا يمكن التأكد منها، وتبرر للحكام كل انتهاكاتهم المريرة والعنيفة تجاه الرعايا بتلك الشرعية المزعومة، وكذلك انتقدت نظرية التبعية الطبيعية التى تتص على ان بعض الناس متفوقون بشكل طبيعي بما لديهح من قدرة في إدارة وسياسة المجموعة الأدنى منهم طبيعيا، وترى هامتون ان هذه النظرية تتناقض بشكل واضح وصريح مع نظريات العلم الصحيحة؛ فعلماء الأحياء المعاصرين ينفون تمامًا منح الطبيعة لإنسان ما طريقة صحيحة للتصرف والعمل والإدارة دون غيره من الآخرين؛ فالعالم لا يحتوي على أي مبادئ معيارية حول من يجب أن يحكم من. فضلا عن كونها تكرس لمفهوم العبودية والعنصرية. وكذلك رفضت نظرية الكمال التى تقوم على فكرة: أن الثخص الذي يمتلك السلطة السياسية، هو الذي يكون لديه المعرفة والخبرة الفائقة التي يستطيع بواستطهما تحقيق الخير والسعادة للمجتمع كما هو الحال عند أفلاطون، حيث كونها خالية من العدالة والمساواة الحقيقية وتؤكد فقط على سياسة النخبة. وتتتقد كذلك نظرية العقد الاجتماعى بثقيها سواء الموافقة عن طريق إبعاد الحاكم من العقد كما هو الحال عند هوبز، أو الموافقة عن طريق الوكالة كما هو الحال عند لوك. 
مجلة وادي النيل للاراسات والبحوث الإنسانية والاجتماعية ـ مجلة علمية محكمة

(ISSN: 2536 - 9555)

\title{
Jean Hambiton's Critical Approach
}

\section{Study in the Genesis of authority}

\begin{abstract}
:
This research revolves around Jean Hambiton's position on theories of the Genesis of authoritin society. She rejected the theory of divine authority as it is more like metaphysical opinions that cannot be ascertained, and justifies the rulers to all their bitter and violent violations towards the subjects with that alleged legitimacy, as well as criticized the natural dependency theory that states that Some people are naturally superior in their ability to manage and politics the group who are naturally lower than them, and Hambiton believes that this theory clearly and explicitly contradicts the correct theories of science; Modern biologists completely deny giving nature to a person a correct way of acting, working and managing other than others; The world does not contain any normative principles about who should rule. In addition to being devoted to the concept of slavery and racism, it also rejected the theory of perfection that is based on the idea: that the person who possesses political power is the one who has the knowledge and the superior experience through which they can achieve the good and happiness of society as is the case with Plato, as it is free from justice and equality Real and emphasizes only the policy of the elite. It also criticizes the theory of social contract with its two parts, whether approval by removing the ruler from the contract as is the case with Hobbes, or approval by agency as is the case with Locke
\end{abstract}

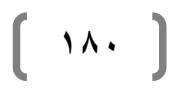




\section{هقدهة:}

جين هامتون فيلسوفة أمريكية معاصرة [190 - 1997 199 أكملت الدكتوراه تحت إشراف جون رولز بجامعة هارفارد Harvard ، وعملت أستاذًا زائرًا بعديد

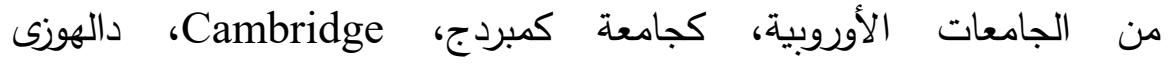
Dathousie وتتتمي إلى أقلية متميزة من الفلاسفة التحليليين الذين يُرف عنهم الالتزام المسيحي بشدة(؟). فكانت تُعرف بالتدين منذ بدء نثأتها فى كنف المسيحية

(2) Farnham, Daniel. " Introduction" The Intrinsic Worth of Persons, Contractarianism in Moral and Political Philosophy, Cambridge, 2007, pp.v, ix

$$
\text { وكذلك راجع }
$$

https://www.jstor.org/stable/3131051 Accessed: 14-11-2018 JSTOR http://wc.arizona.edu/papers/89/150/14_1_m.html

ولـدت جـان إليزابيـث هـامتون في ( يونيـو 90 (1، حصـلت علـى درجـة البكـالوريوس مسن

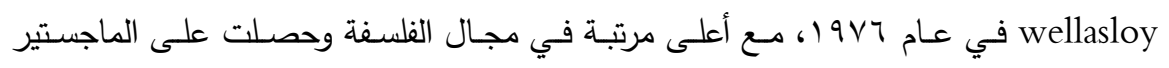

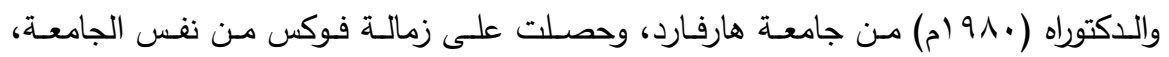

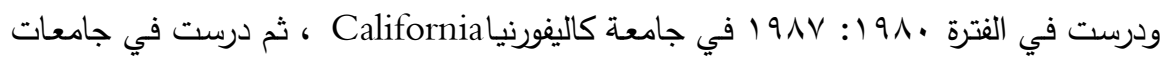

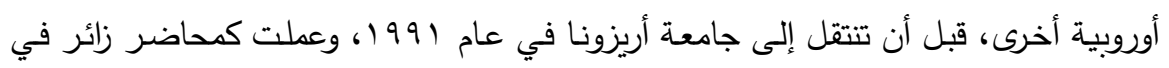
عدد من الجامعات الأوروبية أهمها (نوتردام - دالهوزى - بريستول بإنجلترا)، وشاركت في كثير إنير

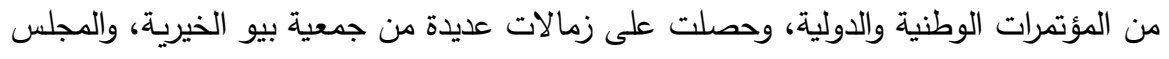

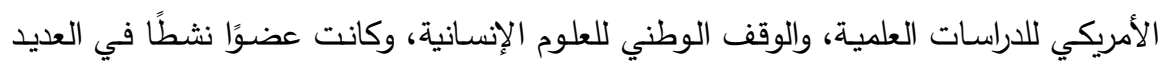
من المنظمات المهنية، وعضوًا في هيئة تحرير ثلاث مجلات فلسفية رئيسية ومعظم أعمالها

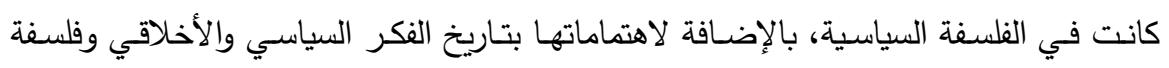

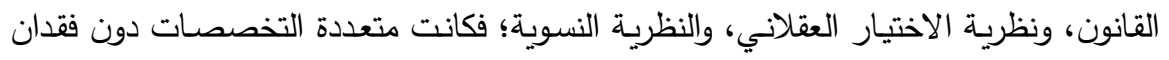

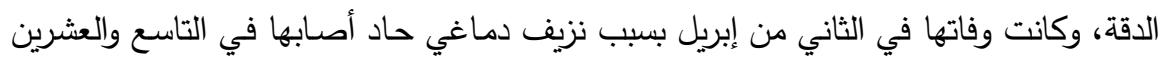
من مارس، وتوفيت بعد ثلاثة أيام نتيجة مضاعفات هذا النزيف وكانت في في الرابعة والأربعين من عمرها؛ فكانت نهاية مبكرة لحياة مشعة بالفكرة.

$$
(|1|)
$$


والتزامها بحضور الدروس الدينية، وكانت تسعى كمسيحية مؤمنة لتحقيق مملكة

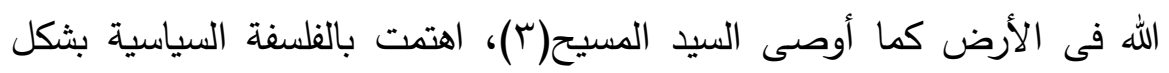

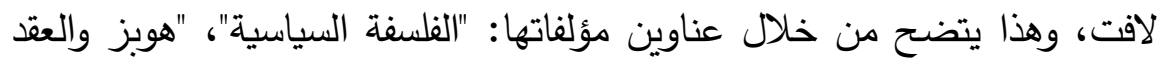
الاجتماعي التقليدي"، "القيمة الجوهرية للأشخاص: التعاقد في الأخلاق والفلسفة

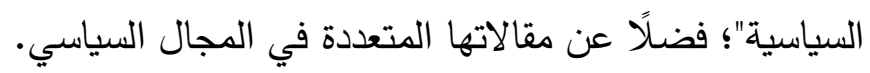

والفلسفة السياسية عند هامتون ليست وصفًا سطحيًا للمجتمعات السياسية، ولا شرحًا لسياسة الدولة اليومية، أو فهم مؤسسة بعينها في الدول لئنسات القائمة، ولكنها

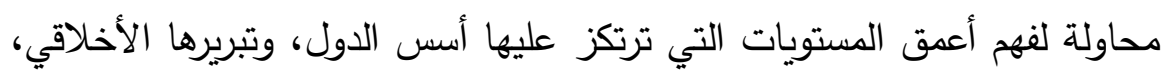

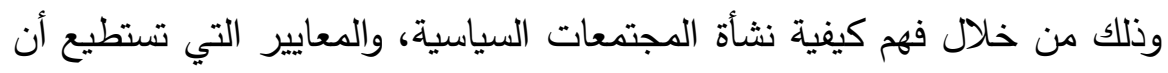
نميز بواسطتها بين المجتمع السياسي المشروع وغير المشروع من النواهي

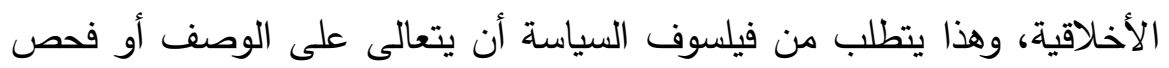

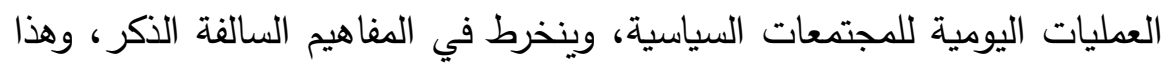

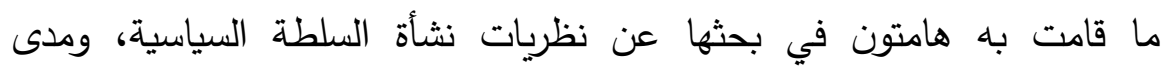

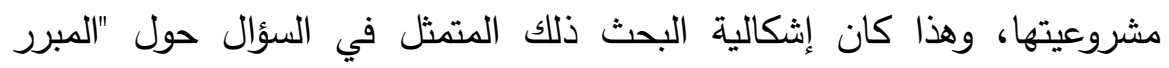

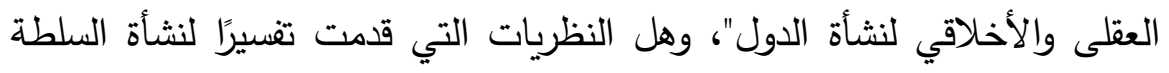

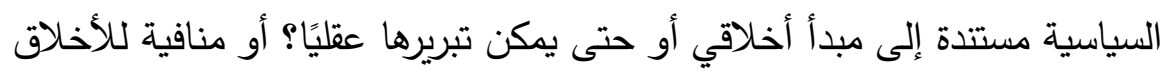

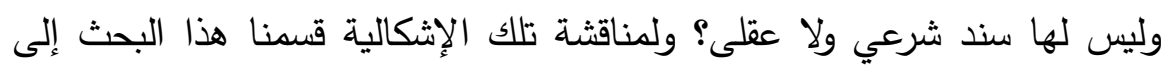
حول السيرة الذاتية للفيلسوف، راجع: Annas, Julia.proceedings and Addresses of the American Philosophical Association, (Vol. 70, No. 2) (Nov., 1996), Published by: American Philosophical Association Stable URL. (pp. 191-193)

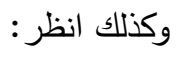

Farnham, Daniel. " Introduction" The Intrinsic Worth of Persons, Contractarianism in Moral and Political Philosophy, Cambridge, 2007.

(3) Hampton, Jean. " Forgiveness and Christianity " Forgiveness and Mercy.jeffrie G.murphy, and Jean Hampton, Cambridge, 1988, p. 180.

$$
\text { ( In })
$$




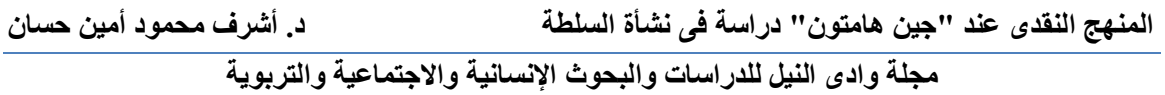

مقدمة وثلاثة مباحث وخاتمة تشمل أهم النتائج التي تم التوصل إليها، وفي المقدمة يتناول الباحث التعريف بالفيلسوفة ومفهوم الفلسفة السياسية عندها، وإثكالية البحث والمناهج المستخدمة في الدراسة فضلًا عن خطة البحث

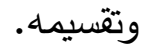

المبحث الأول: مفهوم السلطة السياسية the political authority عند

\section{المبحث الثاني: موقف جين هامتون من نظريات نثأة السلطة}

أولًا: النظريـة الدينية (السلطة الإلهية the divine authority)

ثانيًا: نظرية التبعية الطبيعية (the natural subordination)

$$
\text { ثالثًا: نظرية الكمال المعرفي (the perfectionist) }
$$

رابعًا: النظرية المستندة إلى الموافقة (the consent-based) (العقد

الاجتماعي (the social contract

أولاً: العقد الاجتماعي للوكالة (the agency social contract)

the alienation social ثانيًا: العقد الاجتماعي للإبعاد (الاغتراب) لعناب)

contract

المبحث الثالث: نظرية هامتون في اختراع السلطة

The invention of political authority

الخاتمة: متضمنة نتائج البحث.

وقد استخدم الباحث في دراسته هذه المنهج التحليلي لتحليل المفاهيم والنصوص السياسية، والمنهج النقدي لبيان موقف هامتون النقدي من ناحية وموقف الباحث من ناحية أخرى، بالإضافة للمنهج التاريخي حيث إن الأفكار

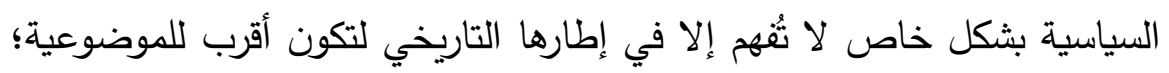

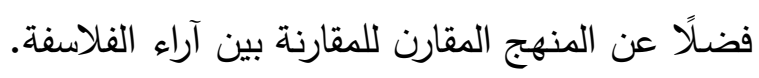




\section{المبحث الأول}

\section{هفهوم السلطة السياسية عند جين هاهتون}

(the political authority)

السلطة السياسية -كما تقول هامتون- هي: أن الثخص (X) وهو هنا الحاكم، لديه سلطة سياسية على الثخص (y) وهو هنا الشعب، وعلى الثخص (X) مع إعطاء (X) المأمور بهاء للقيام (X) الثنيذ العمل (Y) بالعمل (P)؛ فالثعب هنا يخضع باستمرار لقواعد وقوانين مبررة، من أجل تتظيم المجتمع(ء). ابتداء من السلوك في الأماكن العامة مع الكائنات العاقلة وغير العاقلة، مرورًا بالملكيات والضرائب وغيرها حتى قواعد الحروب مع الدول الأخرى(0). وهكذا يتم فرض هذه القواعد من قبل أشخاص معينين وفقًا لتوجيهات أولئك الذين ينشئون هذه القواعد ويحددون العقوبات على كسرها، ومن لم يُطع هذه القواعد وتلك القوانين؛ فسوف يُعاني من عواقب وخيمة غير مرغوب فيها والتي قد تتراوح من غرامات صغيرة إلى السجن وحتى الموت في بعض المجتمعات(؟). وتتساءل هامتون عن هذا الخضوع من جهة الثعب للسلطة؛ هل هو مسموح به حقًا من الناحية الأخلاقية؟ أم هذا انتهاك لحقوق الأشخاص كما يزعم الفوضويون؟ الذين يرفضون الهيمنة السياسية السلطوية، ويرون أن الثكل الوحيد الذي يجب الدفاع عنه أخلاقيًا من الارتباطات البشرية هو الذي لا يوجد فيه

(4) Hampton,Jean.hobbes And The social Contract Tradition,Cambridge 1986, p. 4

(5) Hampton, Jean. " The Retributive Idea " Forgiveness and Mercy, Jeffrie G.murphy, and Jean Hampton, Cambridge, 1988, pp. 156.

(6) Hampton, Jean.political Philosophy, U S A, by Westview Press, 1997, pp5. 
أشخاص أو مؤسسات تصدر أوامر من خلال القوة. وهذا الفكر قد أرق جين هامتون كثيرًا، وحدا بها للبحث عن مبرر للسلطة السياسية في المجتمع ومناقشة جميع النظريات التى تبررها(V).

وهنا تفرق هامتون بين السيطرة المشروعة والسيطرة غير المشروعة، بناءً على المعايير الأخلاقية؛ فمثلا سيطرة الوالدين على طفل صغير وتوجيه سلوكه ليس مسموحاً بها فحسب؛ بل هى مطلوبة من الناحية الأخلاقية، أما سيطرة الثخص المسلح على ضحيته التي اختطفها تحت تهديد السلاح فهى غير مقبولة، وبالتالي يجب إدانة هذا النوع من السيطرة لأنه غير مبرر أخلاقيًا؛ فهو انتهاك لحقوق شخص مجبر ومكره، أما النوع الأول من السيطرة فله مبرر أخلاقي ومتسق مع حقوق الطفل على الوالدين بل ويدعمها(^). وبناءً على هذا المفهوم للسلطة ومدى مشروعيته تناولت هامتون نظريات السلطة السياسية لبيان ما هو المبرر منها أخلاقيًا وما هو غير المبرر، وهذا ما سوف نتتاوله في المباحث التالية.

(7) Hampton, Jean.the Contractarian Explanation of the State, Midwest Studies In Philosophy, (No.xV) (pp. 344-371), (1990), p. 344

(8) Hampton, Jean. " Forgiveness, Resentment and Hatred " Forgiveness and Mercy.jeffrie G.murphy, and Jean Hampton, Cambridge, 1988, p. 39. 


\section{المبحث الثاني}

\section{هوقف هاهتون هن نظريات نشأة السلطة}

\section{أولاً: نظرية السلطة الإهية (النظرية الدينية)}

(the divine authority theory)

يذهب ممثلو هذه النظرية إلى أن سلطة الحاكم مُستمدة في مشروعيتها من الله

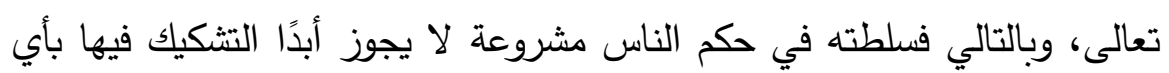
شكل من الأشكال، ولها ثلاث صور من الناحية التاريخية (9): الصورة الأولى: - هذه الصورة تصور الحاكم على أنه إله في شكل إنساني، الحكا،

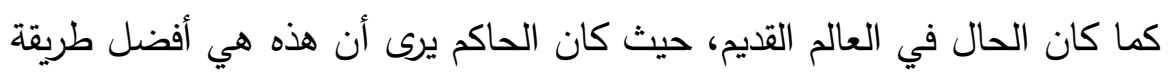
لتأسيس السلطة وإضفاء المشروعية عليها. الصورة الثانية: وفق هذه الصورة يعلن الحاكم نفسه صاحب علاقة بالله بثكل أو بأخر وليس إلهاً، (خاصة أن هذا الإعلان الإلهي قد يكون مشكوكاً فيه من الهن

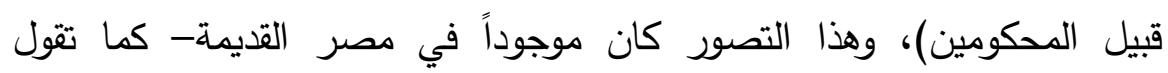

(9) Political Philosophy, p. 7

يطلق على الصورة الأولى فى المؤلفات السياسية، (ألوهية الحاكم) وعلى الصورة الثانية (الحق الإلهى المباشر) وعلى الصورة الثالثة (الحق الإلهى غير المباشر) راجع فى فلى ذلك بالتفصيل:

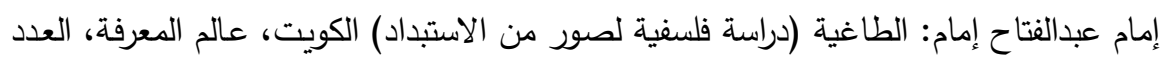

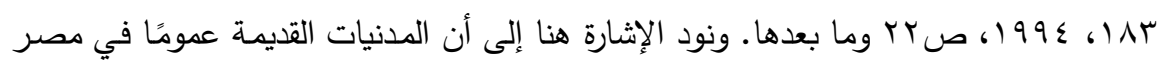

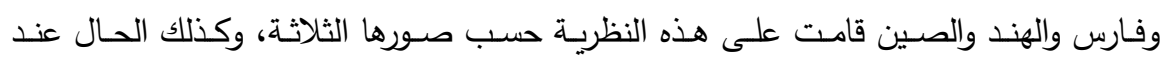
الرومان الذين كانوا يقدسون الإمبراطور ويعدونه إلها؛ فهو الذي يحميهم من شرور الطبينهـ

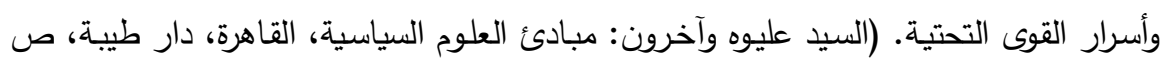


هامتون- حيث كان الحاكم يعلن أنه ابن الإله كما كان موجوداً ببلاد سومر ، أو كما كان يذّعى بعض ملوك العالم القديم أنهم يتغذون من الحليب الإلهي. الصورة الثالثة: وهذه الصورة هي الأكثر شيوعًا، وهي اعتراف الحكام بإنسانيتهم الكاملة ولكن الله هو الذي أعطاهم سلطة الحكم على الناس، وهذا

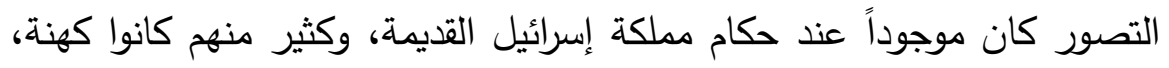
وكنلك كان الحال في العصور الوسطى من قبل باباوات الكنيسة المسيحية؛ فصاروا بذلك الزعم أصحاب السلطتين الدينية والسياسية على كل العالم المسيحي.

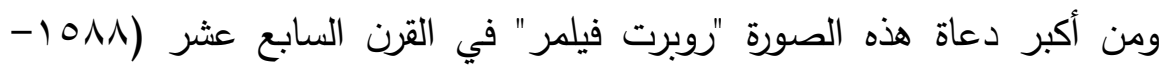

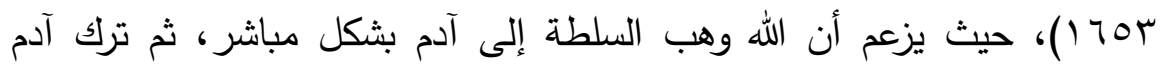

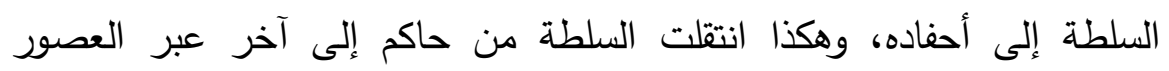
المختلفة حتى وصلت لملوك أوروبا الحاليين.

ورغم أن هذه الصورة هى الأكثر شيوعًا برأى هامتون، إلا أنها لاقت كثيرا من

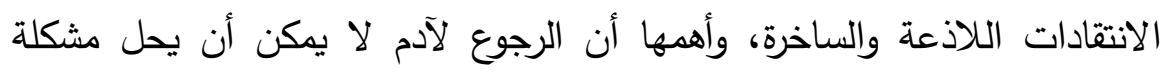

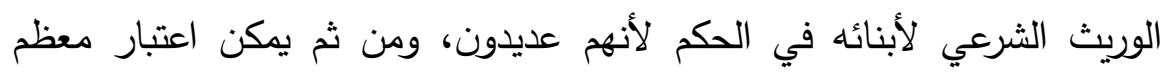

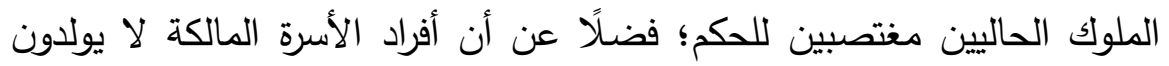

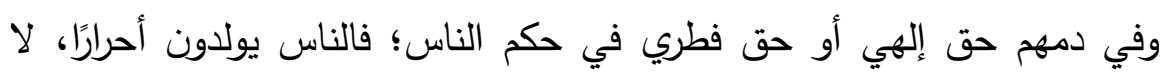
أفكار في عقولهم، ولا فطرة في دمائهم تجعل بعضهم يتميز عن بعض فئهم الآخر .

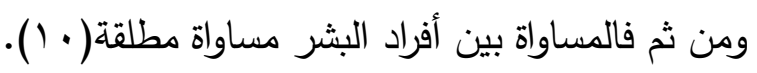

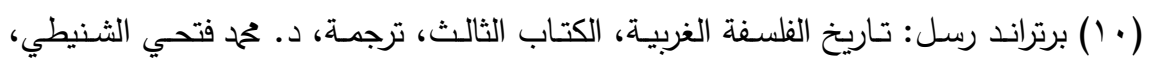

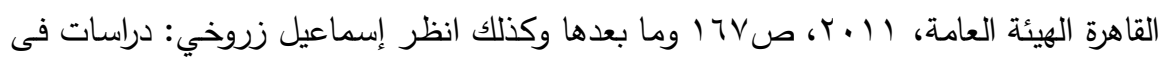

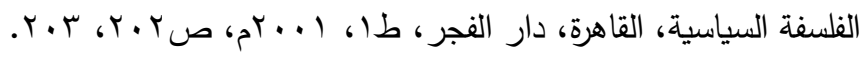


وتتنهى هامتون إلى أنه وفق هذه النظرية بصورها الثلاثة يخضع الرعايا

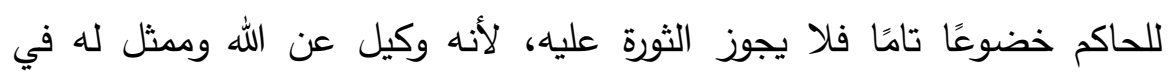

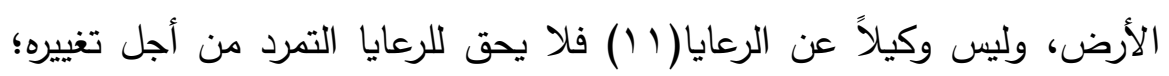

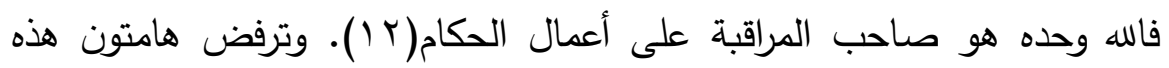

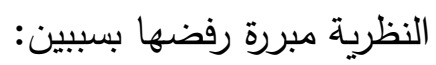

الأول: لا يستطيع أي حاكم يدعى أي صورة من تلك الصور الثلاثة أن يثبت

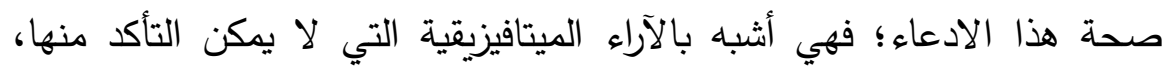

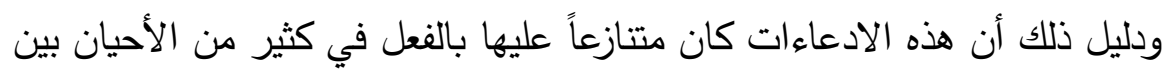

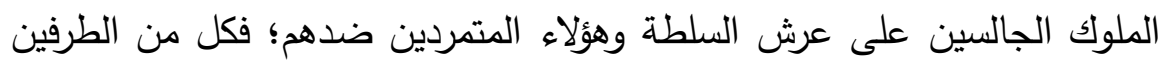
يدعي الحق الإلهي في الحكم، دون أي إثبات لادعائه، حيث لا لإئ يكن إثباته أبدًا،

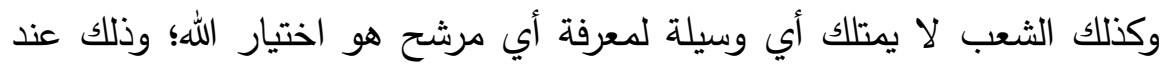

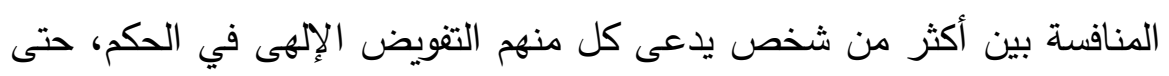

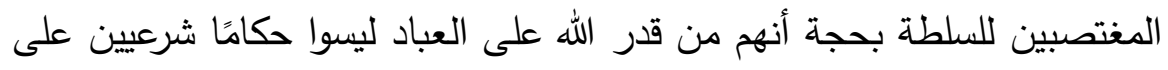

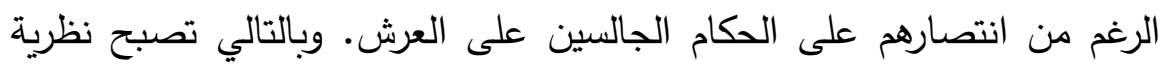

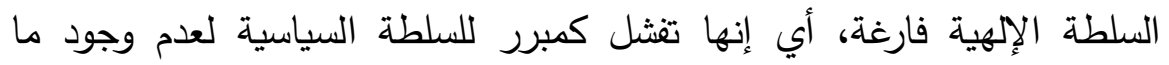

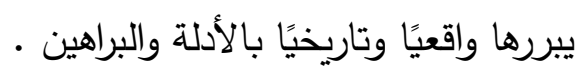

أما السبب الثاني لرفض هامتون لتلك النظرية وهو الأهم بنظرنا: أن القول باستمداد السلطة السياسية من الله يجعل سلطة الحكام سلطة مطلقة غير محدودة النطاق والمحتوى، وعليه يبرر الحكام كل انتهاكاتهم المريرة والعنيفة تجاه الرعايا بتلك الثرعية المزعومة. لذلك كوكما تقول هامتون- نجد العديد من الفلاسفة

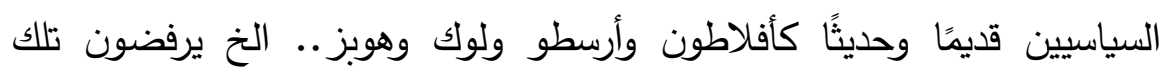

(11) Hobbes And The social Contract Tradition, p. 264.

(12) Hampton.political Philosophy, p. 8.

$$
(111)
$$


النظرية لأن تمريرها سيكون له خطر في أيدي الحكام المعدومى الضمير

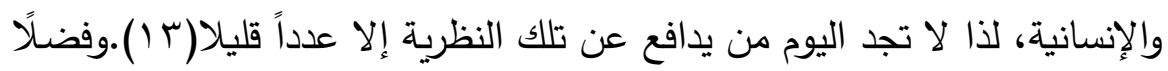

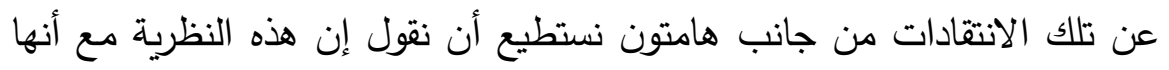

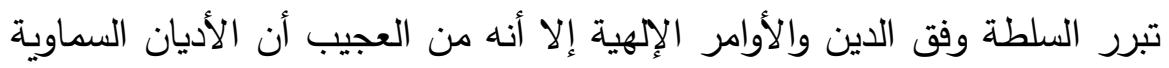

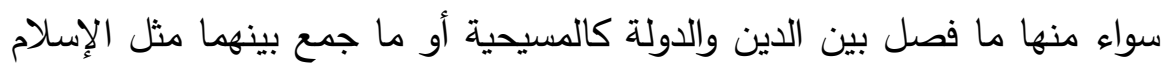
لم تقر بهذه النظرية فلم نجد في أى إصحاح أو آيه قرآنية ما يدعمها. ثانياً: نظرية التبعية الطبيعية (the natural subordination theory) تقوم هذه النظرية على الاعتقاد بأن بعض الناس متفوقون بشكل طبيعي بما

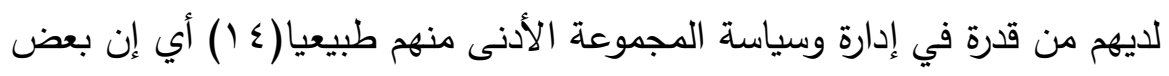

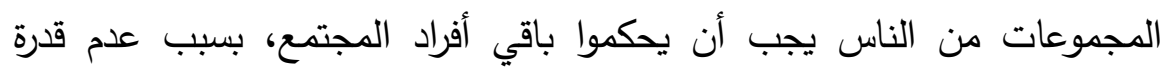

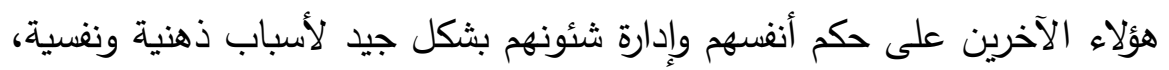
حيث إنهم يعانون من نقص شديد في التفكير والإدارة، بسبب كونهم غير مؤهلين

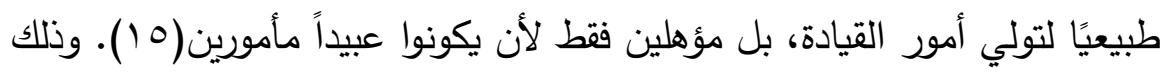

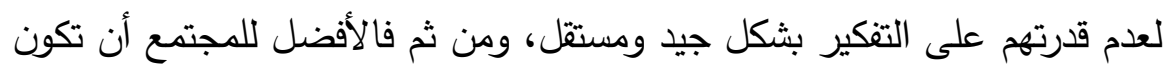

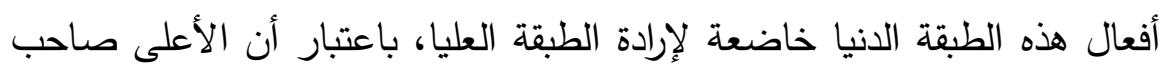
تفوق عقلاني يساعده على توجيه الأدنى للتصرف بطرق تحفظ سلامته وسلامة الإنة الأنها

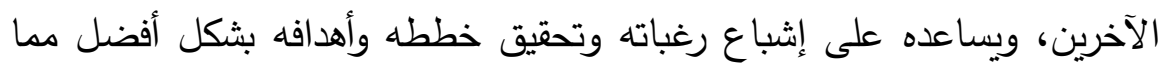
يستطيع أن يفعله بمفرده( (1 ).

(13) Political Philosophy, pp. 9, 10.

(14) Hobbes And The social Contract Tradition, p. 264.

(15) The Contractarian Explanation of the State, p. 345.

(16) Political Philosophy, p. 14.

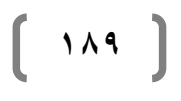


فأصحاب السلطة والمهيمنين عليها يجدون في أنفسهم أن طبيعتهم تتتاسب مع السلطة والحكم والهيمنة؛ فهذه النظرية تقوم إذن على فكرة عدم تساوي الناس بما فيه الكفاية في القرات والمواهب، وبناءً عليه يجب على البشر الموهوبين السيطرة

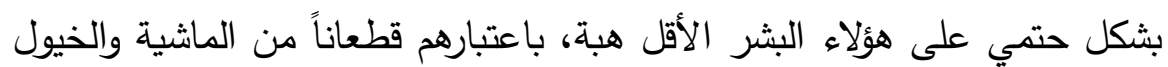

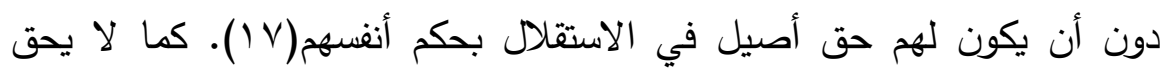

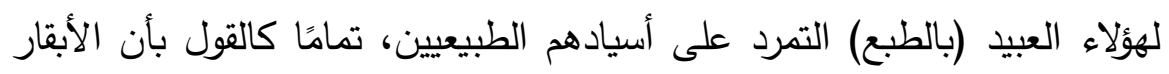

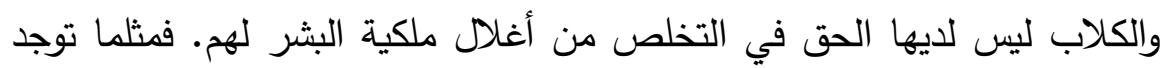
قوانين طبيعية تحكم العالم الطبيعي؛ فهكا توجد قوانين طبيعية تحدد بشكل ثابت

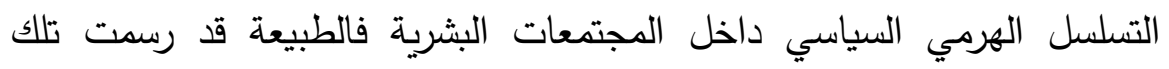
الهيمنة بما تحتويه في داخلها من قوانين وقواعد معينة يجب أن تحكم سلوكنا

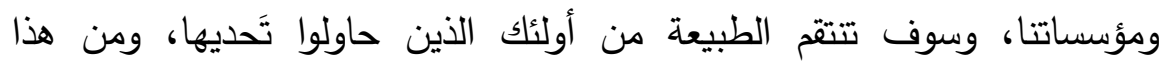

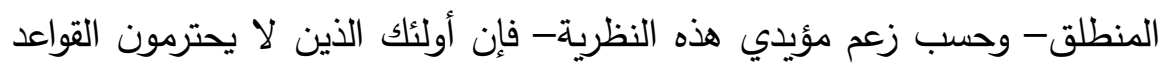

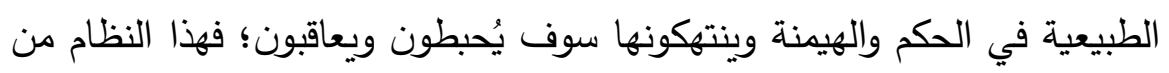
العبودية الطبيعية يُضفى الشرعية على نتائجها لكل من السيد والعبد(1 (1). وترى هامتون أن بذور هذه النظرية وجدت منذ الفيلسوف أرسطو على الرغم من عدم تطويره لها بثكل جوهري سياسيًا- حيث إنه يقر بثكلين من أثكال الهيمنة الطبيعية: هيمنة السيد على العبد وهيمنة الرجال على النساء وذلك

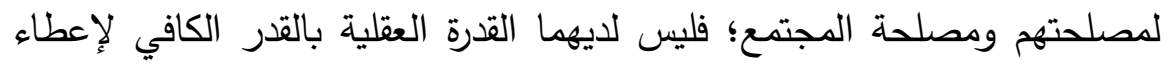

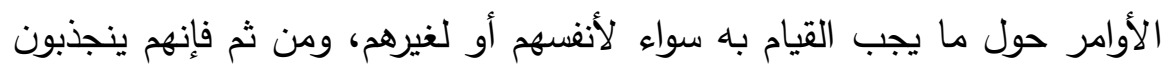

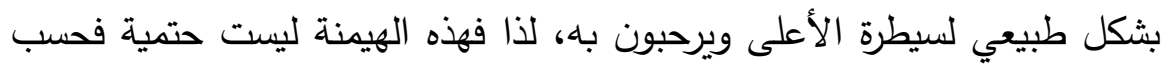

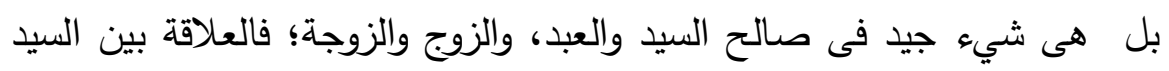

(17) Hampton.political Philosophy, pp. 10, 11.

(18) Political Philosophy,, pp. 16, 17.

$$
(19 \cdot)
$$


والعبد والزوج والزوجة، مثلا علاقة النفس بالجسد على حد تعبير أرسطو(9 (1). فأرسطو هنا يرفض دعوة أفلاطون بمساواة الرجل بالمرأة في كافة الأعمال، مناديًا

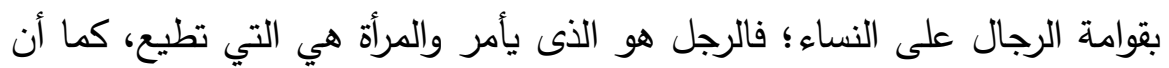

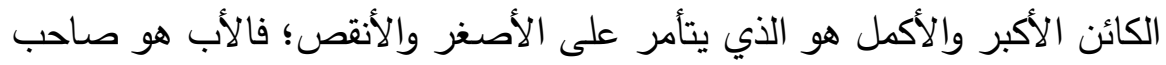

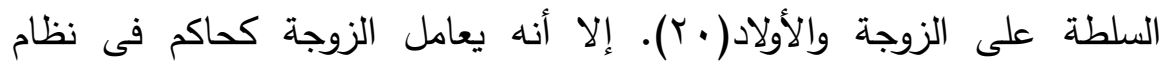

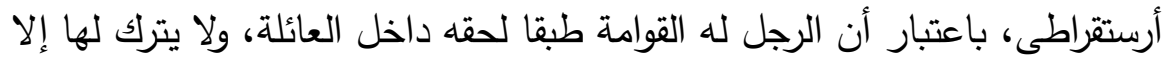

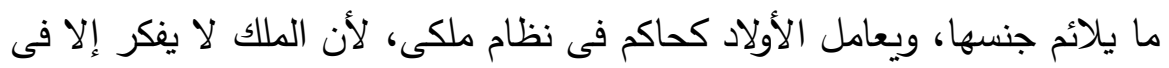
مصالح رعاياه، لذلك كانت الملكيه أثبه للسلطة الأبوية( (Y).

وقد فسر أرسطو موقفه هذا في التفاوت بين الرجل والمرأة تفسيرًا طبيعيًا، حيث إن بعض الكائنات مخصصة لللطاعة منذ الولادة والآخر مخصص للإمرة، كما هو الحال في الكائن الحي حيث نرى النفس تأمر والبدن يطيح؛ فالنفس تتسلط على البدن كسيد على عبده، والعقل يسيطر على الغرائز كالحاكم على شعبه، ومن ثم تصبح المساواة أو انقلاب السلطة بين تلك الأنواع المختلفة شرًا للجميع

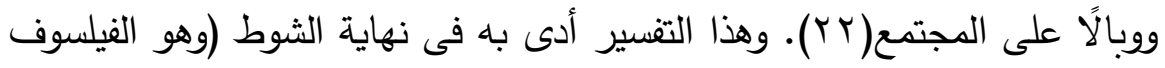

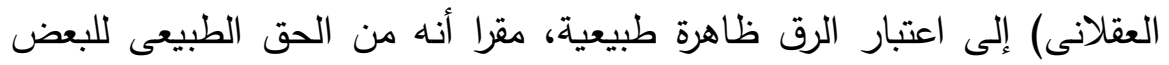

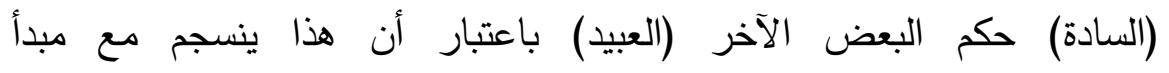

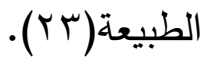

(19) Hampton.political Philosophy, pp. 14, 15

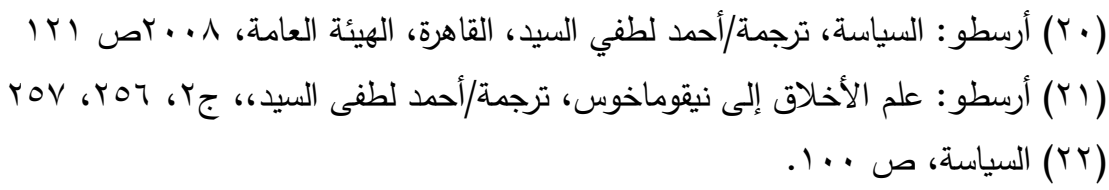

(23) Lernr, Max. " Introduction" Aristotle's Politics, translated by Benjamin Jowett, the Modern Library, New York, p. 13 
فالدولة حسب هذا الزعم الأرسطى لا تتكون من أفراد اجتماعيين منعزلين كما

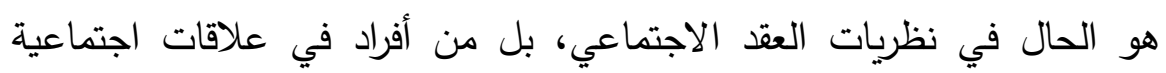

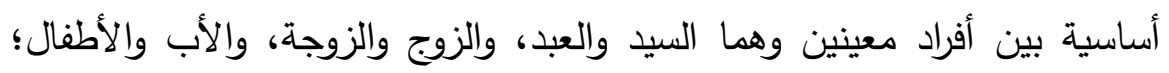

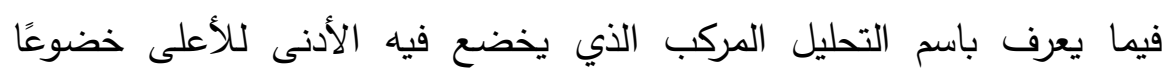

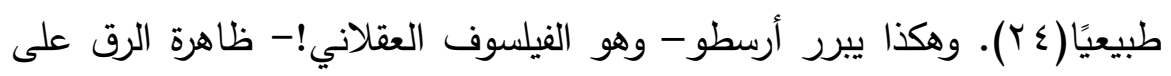

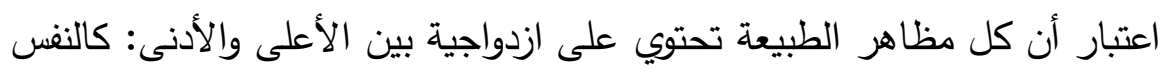

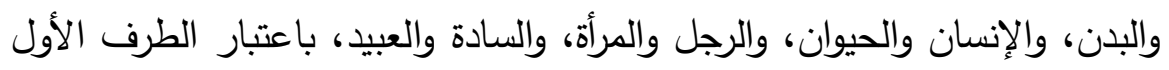

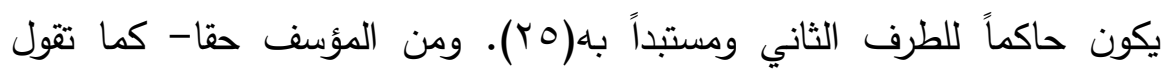
هامتون- إنه تم الدفاع عن هذه النظرية حديثًا من قبل مؤيدي العبودية بأمريكا

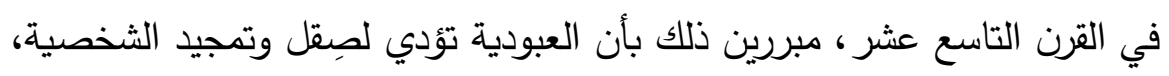

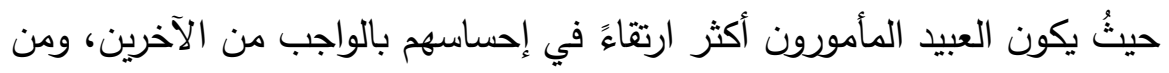

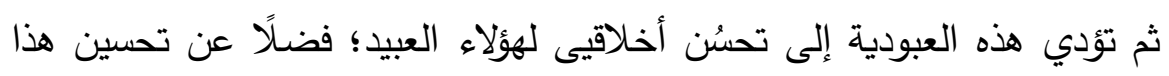

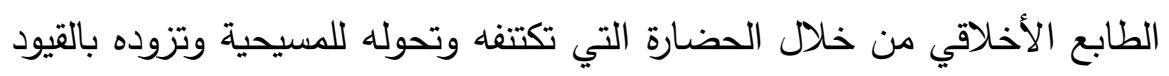
التي تبقيه على المسار الأخلاقي دون أي فجور ؛ فنظام التبعية القائم على مفهوم

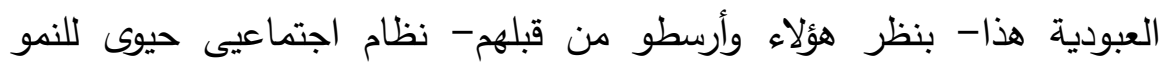

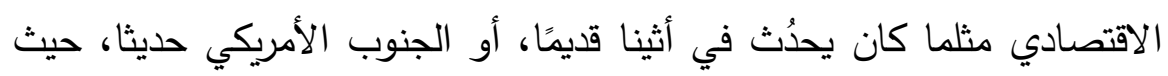

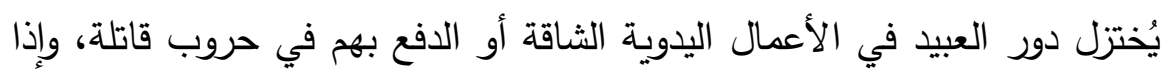

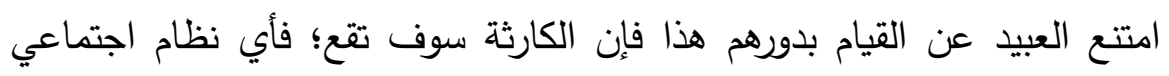

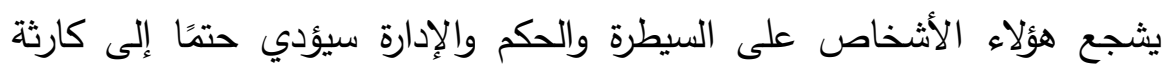

(24) Hobbes And The social Contract Tradition, p. 8

(Yo) برتراند رسل: حكمة الغرب، ترجمة: د. فؤاد زكريا، الكويت، عالم المعرفة، العدد ـ ـrا،

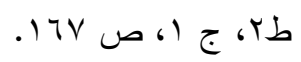


اقتصادية وثقافية وعسكرية وقانونية للمجتمع، وربما يكون هذا هو السبب- برأي هامتون - لدعم هذه النظرية قديمًا وحديثًا (T ب).

والحق أن هناك مبررات أخرى دفعت أرسطو للقول بنظرية التبعية الطبيعية هذه ألا وهى الميراث البيئي من عادات وتقاليد وعقائد وثقافة... الخ حيث كان نظام الرق عنصرًا أساسيًا للنظام الاقتصادي، كتميز النظام الرأسمالي الحديث بوجود طبقة البلوتاريا أصحاب الأجور؛ فالنظرية السياسية عند اليونان مبنية أساسًا على التسليم بنظام الرق(YV) وإلا كيف نبرر موافقة أرسطو وأفلاطون من قبله على ذلك النظام الإنساني ؟! وهما مشهوران بالاتجاه العقل! فرغم حديث أفلاطون عن المدينة الفاضلة إلا أنه أيضًا لم ينصف طبقة الرقيق التي كانت تقوم بأشق الأعمال والتي بها قامت حضارة اليونان، ولم يفكر مطلقًا في إلغاء نظام الرق؛ في الوقت الذي فيه ظهرت دعوة معاصريه من السوفسطائيين لإلغائه لما فيه من ظلم وقسوة، باعتباره نظاماً مصطنعاً وليس طبيعيا- كما يزعم أفلاطون وأرسطو - إلا أن كل من أفلاطون وأرسطو نظرا إليه باعتباره نظاماً مفروضاً بالطبيعة(r^). ومن المؤسف حقا: أن ارسطو لم يقف عند مجرد التسليم

(26) Hampton. political Philosophy, pp. 15, 17

جورج سـباين: تطـور الفكر السياسـي، ترجــة: حسـن جـال العروسي، تصـدير : د.

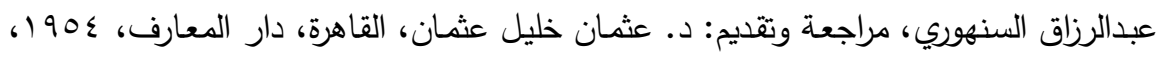
ج)

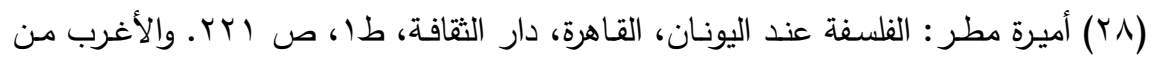

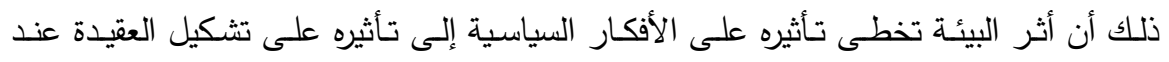

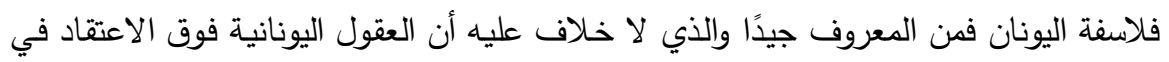

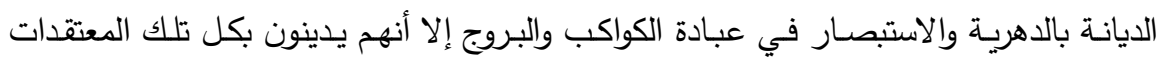

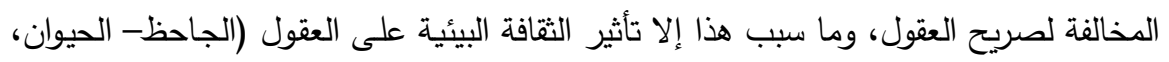

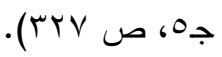


بنظام الرق بل نزع إلى التبرير الطبيعى له؛ ففارق بذلك الموضوعية العلمية، وانحنى أمام العرف الجارى، وحاول سنده بمبررات عقليه، وهذا التبرير من جانبه

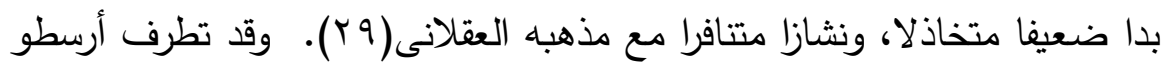

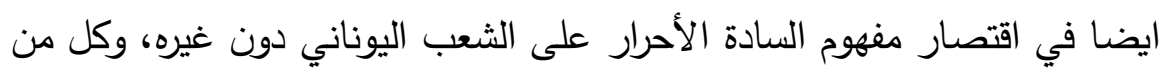
عداه يكونون عبيدًا لهم وبرابرة؛ فكل الشعوب غير اليونانية رغم ما تمتلكه من الثناني مميزات وسمات إيجابية، لا يصلحون إلا للخضوع لغيرهم من اليونان( • ب). وتعارض هامتون هذه النظرية بقوة لعدد أسباب: أولها: أن هذه النظرية تتناقض بثكل واضح وصريح مع نظريات العلم

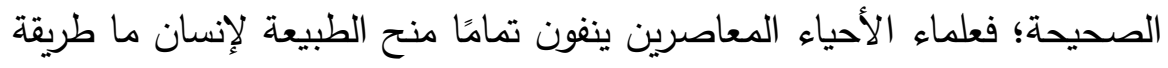

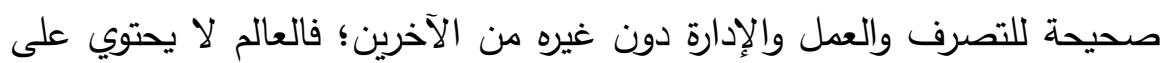

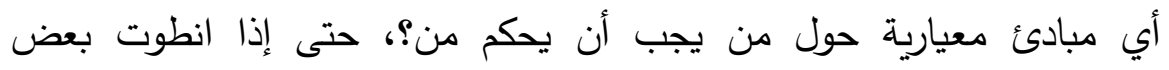
الدراسات على تفوق بعض السلالات على الأخرى فهذا ليس مدعاة لإثبات صحة

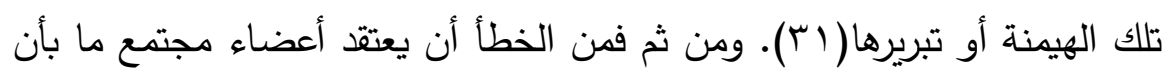

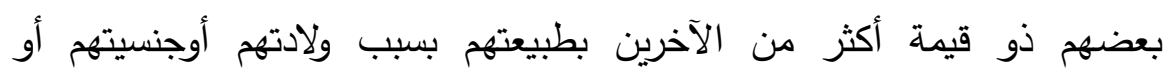

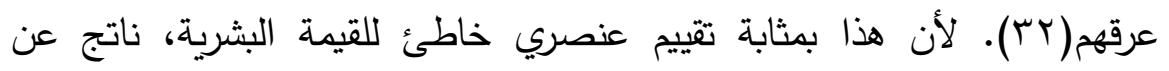

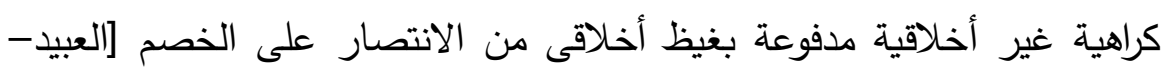
السود- النساء] دون مبرارات أخلاقية(r؟). وهذا بمثابة هيمنة ثقافية لإظهار

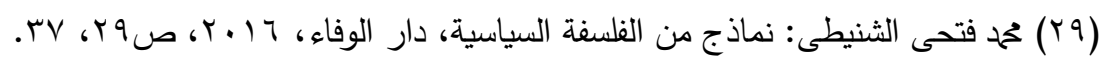

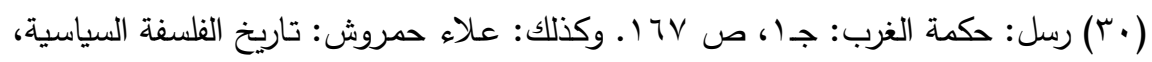

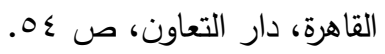

(31) Political Philosophy, p. 13

(32) The Intrinsic Worth of Persons, p. 36

(33) Forgiveness, Resentment and Hatred, pp. 56, 61 
النساء أضعف عقليا من الرجال، والسود أقل شأنا من البيض، والعبيد أقل مكانة

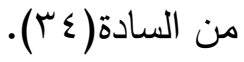

وثانيها: أن هذه النظرية تُكرس لمفهوم العبودية والعنصرية، وتمنحهما الغطاء الثرعي؛ ففي ضوء هذه النظرية يكون هناك معاملة تعسفية يتلقاها العبيد على أيدي أسيادهم بثكل سخيف أخلاقيًا، ويجد فيها الأسياد مؤيدو الاسترقاق والعبودية نوعًا من التبرير الأخلاقي لراحة الضمير تجاه أفعالهم الظالمة من أجل التصالح مع أنفسهم ومع الآخرين.

وثالثها: تشير جميع الأدلة إلى أن الناس متساوون بالفعل فيما يتعلق بموضوع الإدارات بثكل عام كلٌ حسب نطاقه، وإذا افترضنا مع أصحاب هذه إنى النظرية - كما تقول هامتون - عدم وجود مساواة بين فئات البشر ؛ فهذا النوع من اللامساواة نادرًا ما يتم تعريفه بدقة، ولا يتم إيضاح: هل هذه اللامساواة خاصة

$$
\text { بموضوعات السلطة أو لا؟(ب)). }
$$

فلا يستطيع أحد أن ينكر عدم توافر المساواة التامة بين شخصين في كافة الصفات والقدرات المختلفة؛ فهذا من الصعب حدوثه، ولا يمكن الاعتراف به(ب). فالناس تختلف فيما بينها عقليًا وجسديًا ومزاجيًا؛ فبعض الناس أكثر ذكاءً أو قوة أو فضلًا من الآخرين، لكن هذه الاختلافات ليست ذات صلة بهيمنتهم السياسية؛ فإذا كان لشخص ما قوة عقلية أكبر من الآخرين؛ فهذا لا يبرر حكمه لهم، ولم يمنح الذكاء المتفوق "لألبرت أينشتاين" الحق في الحكم والسيطرة، بل تم توجيه الذكاء بشكل مفيد لفهم العالم والسيطرة عليه، ولا يعتقد عاقل أنه بحكم ذكائه كان يجب أن يُمنح السلطة السياسية، وكذلك الحال في

(34) Hampton, Jean.the Authority of Reason.edited by Richard Healey, Cambridge, 1998, p. 21.

(35) Hampton.political Philosophy, pp. 15, 17.

(36) The Intrinsic Worth of Persons, p. 33.

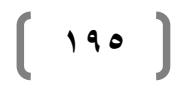


صفات الثجاعة الفائقة والأفضلية... الخ فكل هذه الصفات لا تمنح أصحابها

$$
\text { الحق التلقائي في حكم الآخرين(rV). }
$$

ورابعها: أن أصحاب هذه النظرية والمدافعين عنها، والذين يريدون فرض النها

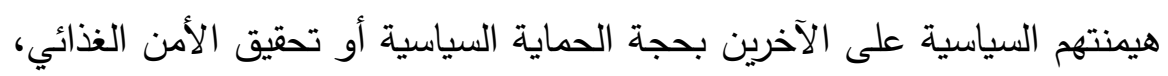

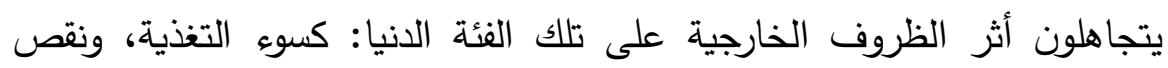
فرص التعليم الجيدة، وسوء الإسكان، وعدم الحصول على فُرص عمل لُعل لائقة...

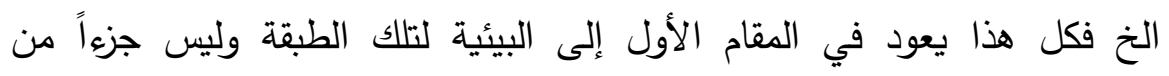
طبيعتهم(r). (1).

وخامس تلك الأسباب: أن علاقة السيد بالعبد هذه قد تفثل عند الاختبار في

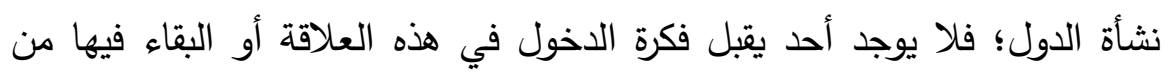

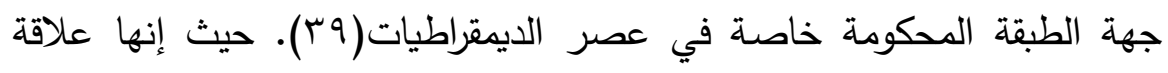

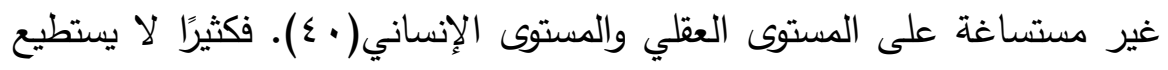
الأسياد من الطبقة العليا السيطرة بثكل دائم على أتباعهم من الطبقة الدنيا، لأن

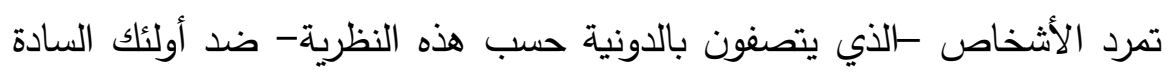

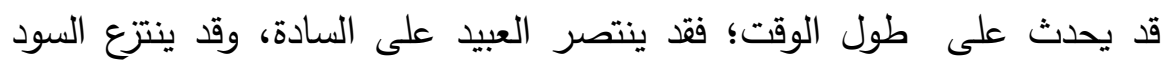
السلطة من البيض، وقد يصعد النساء إلى عرش السلطة بدلًا من الرجال، وقد لفّل

$$
\text { ينتزع الفلاحون السلطة من النبلاء( (؟). }
$$

السبب السادس: وجود تناقض داخلي يكمن في هذه النظرية؛ فإذا كان مؤيدو

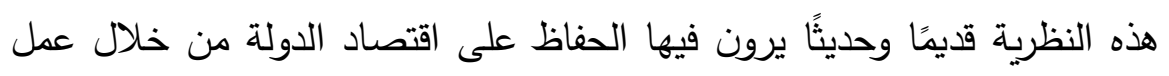

(37) Political Philosophy, p. 18

(38) Political Philosophy, p. 21.

(39) The Intrinsic Worth of Persons, p. 32

(40) Hobbes And The social Contract Tradition, p. 264

(41) Political Philosophy, p. 13. 
تلك الفئة الدنيا؛ فهذا يعني براعة هذه الفئة وتوجيههم العقلاني، لأن اقتصاد الدولة يتطلب القيام بمهام معقدة للغاية، تحتاج إلى قدر كبير من العقلانية والحكم

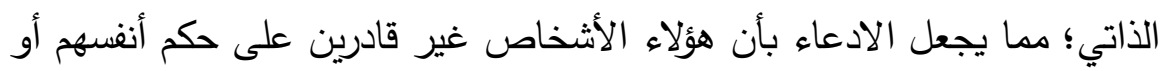

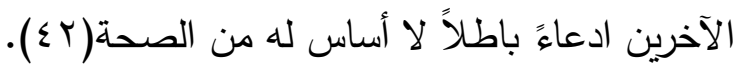

وآخر هذه الأسباب: أن هذه النظرية تُكرس لهيمنة المجتمع الذكوري وتهميش

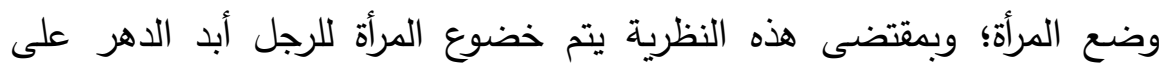
المستوى الاجتماعي، ويتم تهميشها على المستوى السياسي فليس لها الحق في لهاني

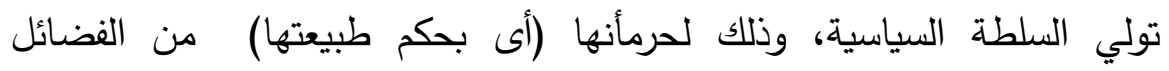

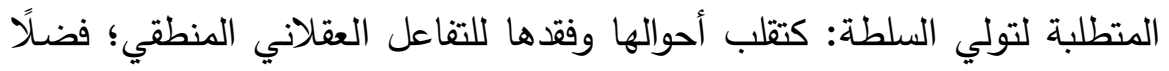
عن الخجل والميل إلى الذعر، والكراهية لمشاركة الجمهور، وعدم قدرتها عن

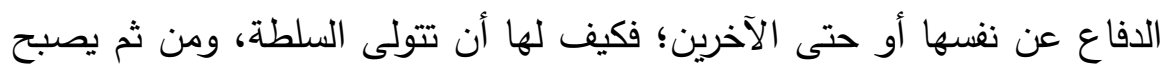

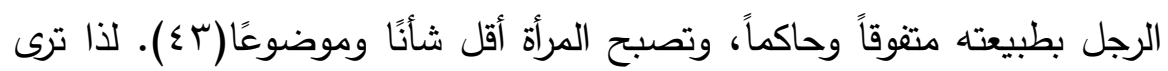

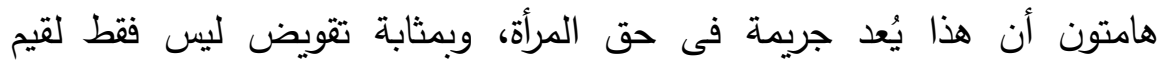

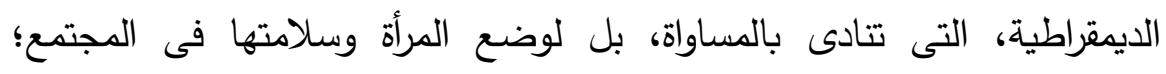

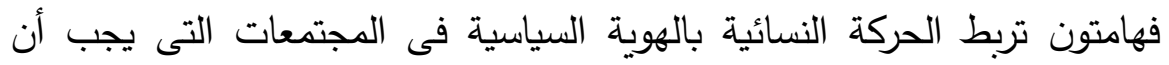

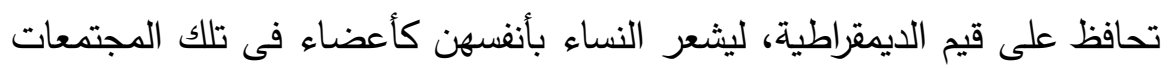

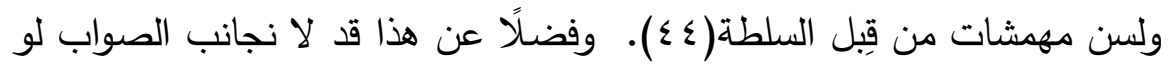

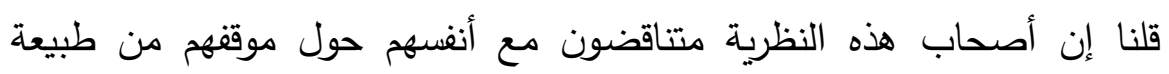

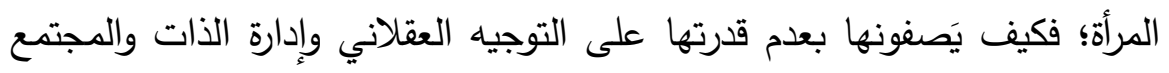

(42) Hampton.political Philosophy, p. 20

(43) Political Philosophy,, pp. 11, 17, 18

(44) Dagger, Richard. "Jean Hampton's Theory of Punishment" a Critical Appreciation.aPA, Newsletter on Philosophy and Law, (Volume 10, no. 2) (Spring 2011), p. 10

$$
(19 v)
$$


من أجل تهميشها سياسيًا، وفي نفس الوقت يسندون إليها إدارة المنزل وإعداد

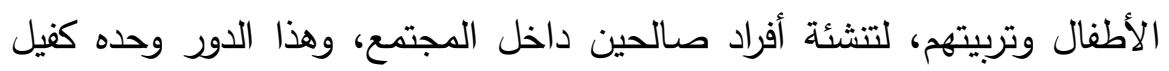
بإثبات قدرتها على إدارة الذات وإدارة الآخرين.

وأخيرًا تتتهي هامتون إلى أن كل الفلاسفة السياسيين والأخلاقيين المعاصرين

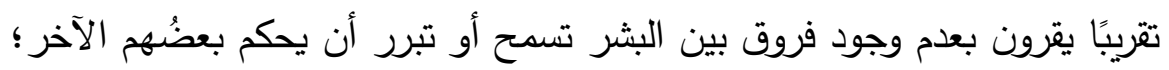

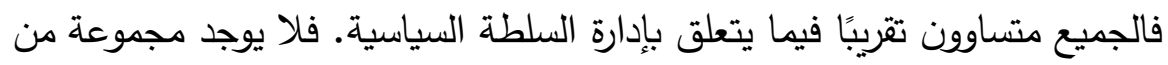

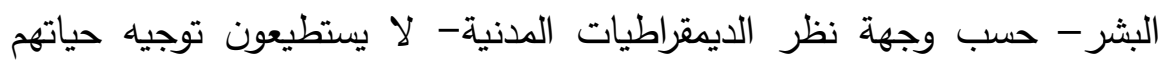

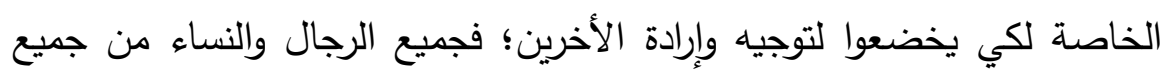
الجنسيات والطبقات يختارون بإرادتهم كيف يقودون حياتهم وحياة أسرهم ويتحملون

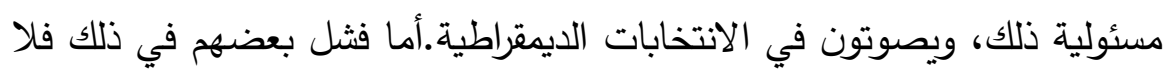

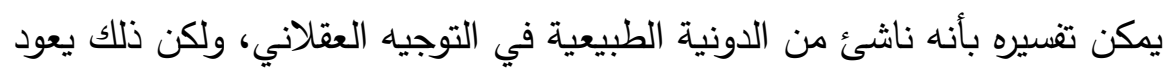

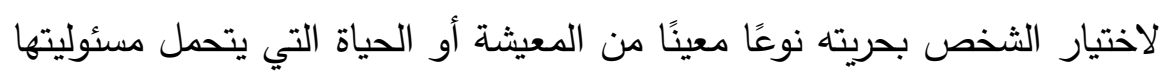

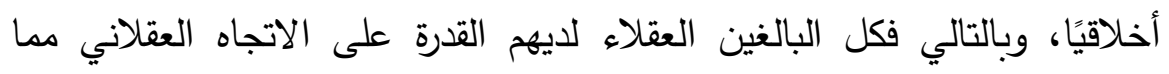

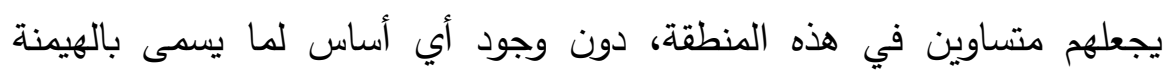

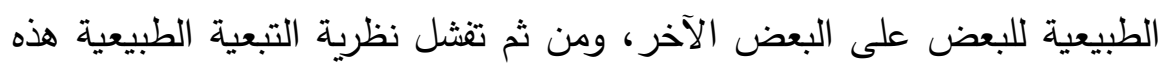

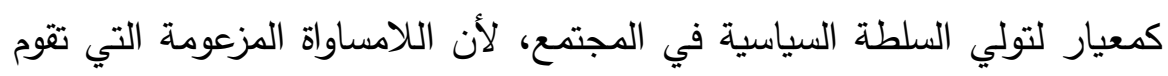
عليها هذه النظرية لا وجود لها(0 ؛ ).

فجميع البشر يمتلكون القدرة العقلانية على فهم طبيعة العالم ليس المادي فقط بل العالم الأخلاقي والاجتماعي الذي يجب على الجميع احترامه، ومهما اختلفت

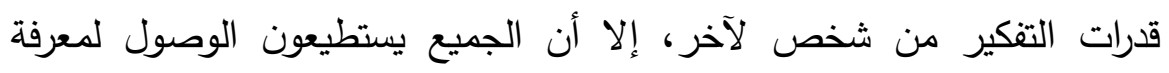

(45) Political Philosophy, pp. 22

$(191)$ 
الحقائق في نهاية المطاف، وذلك من خلال التفكير المنطقي، وهذه المعرفة هي التي تمكننا من بناء مجتمع سياسي شرعي وفعال(T ع). ثالثا: نظرية الكمال (the perfectionist theory): تقوم هذه النظرية على فكرة: أن الشخص الذي يمتلك السلطة السياسية، هو الذي يكون لديه المعرفة والخبرة الفائقة التي يستطيع بواستطهما تحقيق الخير والسعادة للمجتمع، والاتجاه به نحو الأفضل من أجل حياة سعيدة للرعية تقوم على العدل والخيرية، وهذه النظرية تسمى تاريخيًا- كما تقول هامتون- نظرية الكمال للسلطة السياسية. وتعود جذور هذه النظرية إلى أفلاطون [VYV ق. م] الذي أقر وكرر مرارًا وتكرارًا (بالجمهورية) أن الذي يتولى السلطة في المجتمع ينبني أن يعرف كيف يسعد الجميع، ويحقق لهم الخير ويطبق فيهم العدالة -بالمعنى الأفلاطوني حيث توزع الوظائف على الطبقات الثلاثة كلٍ حسب قدراته أكانوا حكامًا أم حراسًا أم مهنيين - فالسلطة السياسية هنا مشتقة من الخير نفسه أو هي الخير في ذاته، والحاكم هنا يمثل الجزء العاقل (الفيلسوف) الذي يحكم كلاً من الجزء الغضبي (الجيش) والجزء الشهواني (المهنيون) فالجزء العاقل هذا هو الذي يسيطر على الرغبات الثهوانية ويهدئ الروح المعنوية (الجيش)الذي قد يصيبه نوبات غضب وعنف لا يمكن السيطرة عليها،- من أجل الوصول

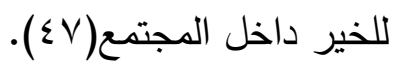

(46) Hampton, Jean, etal.the Idea of Democracy.edited by David Coop, Jean Hampton, and John E.roemer, Cambridge, (1993), p. 301.

The Intrinsic Worth of Persons, p. 160

(47) Hampton.political Philosophy, p. 23

حول التماثل بين طبقات المجتمع وقوى النفس الثلاثة، راجع: جمهورية أفلاطون، ترجمة فؤاد

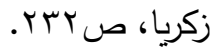


وهذا الجزء العاقل- كما تقول هامتون- هو الفيلسوف الذي استطاع حسب

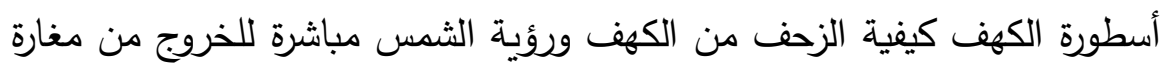
الجهل ليرى الأشياء كما هي على حقيقتها، ثم يعود ليوجه الأشخاص إلى من لئه

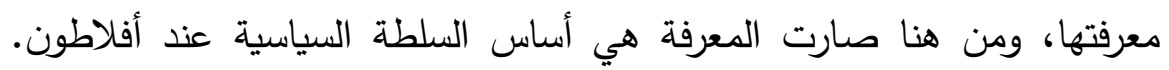

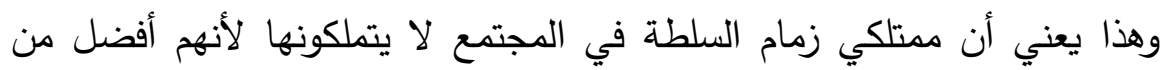

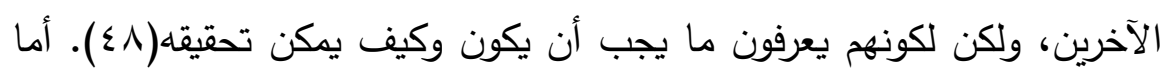

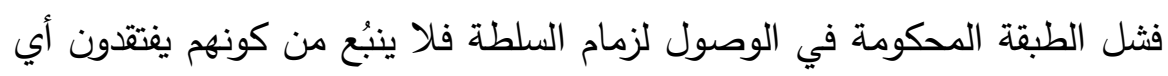

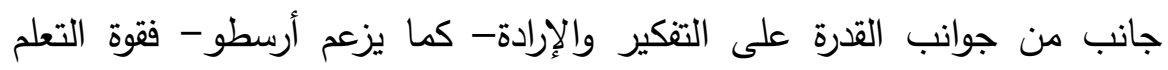

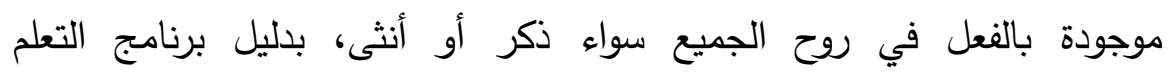

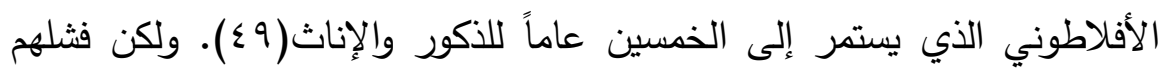

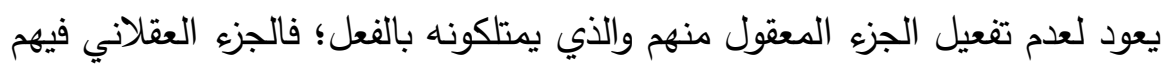

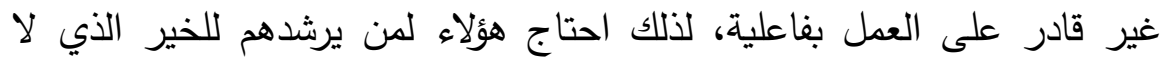

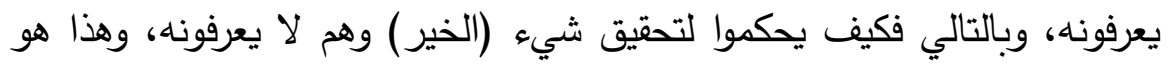

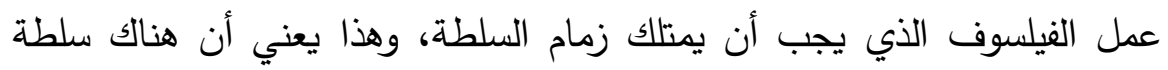

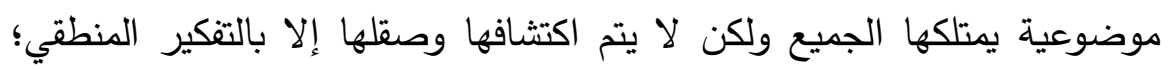

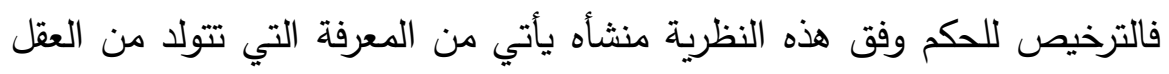

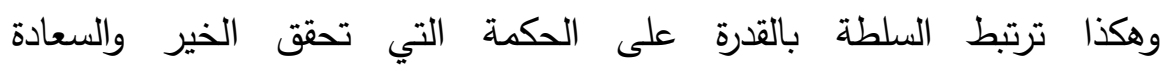

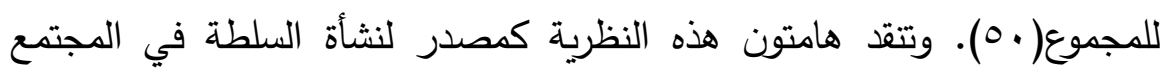

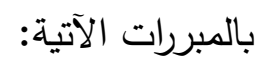

(48) Political Philosophy, p. 2

$$
\text { حول حكم الفيلسوف راجع بالتفصيل: جمهورية أفلاطون، ص00 roo وما بعدها. }
$$

(49) Political Philosophy, p. 6.

(50) Political Philosophy, pp. 25, 26

$$
(r \cdot .)
$$


1- أن إقرار أفلاطون وإصراره على عدم المساواة الجوهري في تفعيل الجزء المعقول المنطقي الموجود لاى الجميع يؤدي إلى القول بأن هذه النظرية خالية من

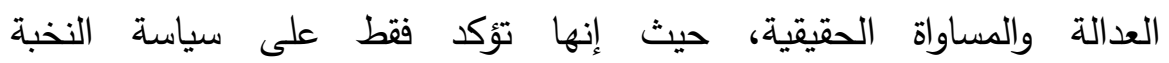

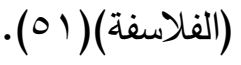

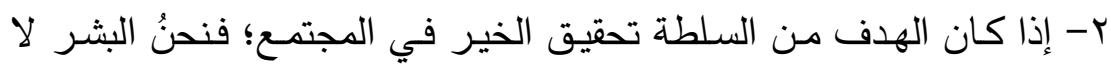

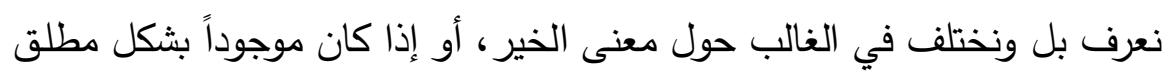

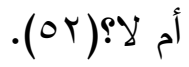

r- أن التصديق بهذه النظريـة يؤدي إلى القول بأن كل السلطات السياسية

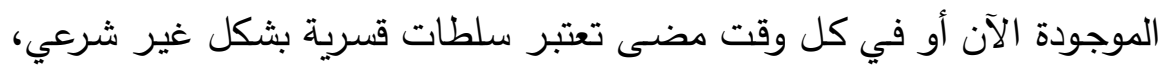

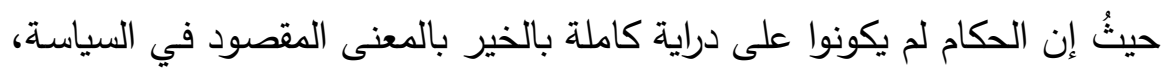

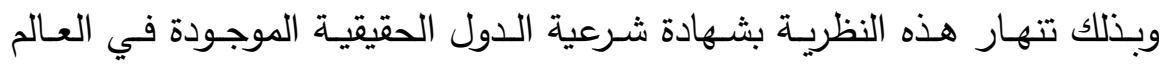

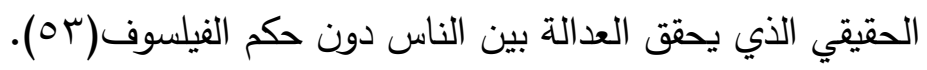

وبجانب هذه الانتقادات كذلك لا نجانب الصواب لو قلنا- كما قال المفكر فؤاد

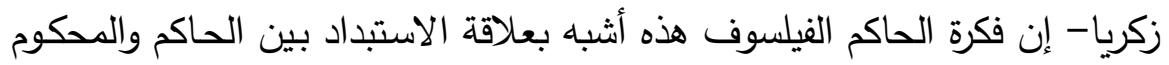
وليست علاقة مشاركة؛ فهي علاقة توجيه وأمر من جانب (الحاكم) وطاعة من الن النان جانب آخر (المحكومين) وهذا لا يتماشى مع طبيعة الفيلسوف وأفكاره الذي يؤمن توند

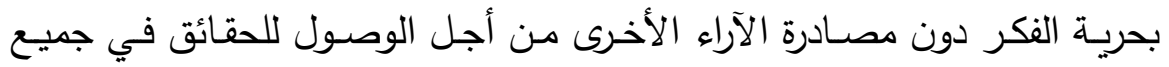

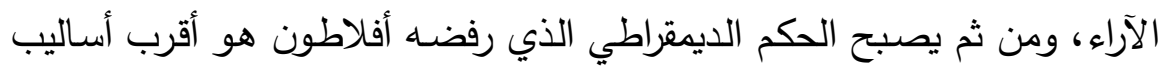
الحكم إلى طبيعة الفيلسوف( ع ه). وهذا ما أكدت عليه هامتون كذلك، حيث ذهبت

(51) Political Philosophy,, p. 27

(52) Political Philosophy,, p. 27

(53) Political Philosophy,,pp. 27

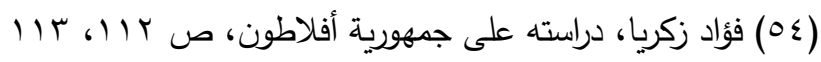

$$
(r \cdot 1)
$$


إلى أن على الفيلسوف السياسي أن يكون متسامحا بصورة فعلية مع كافة الافكار السياسية المتنوعـة بـالمجتمع، وان يحترم جميع المعتقـدات والحريـات، ويحترم

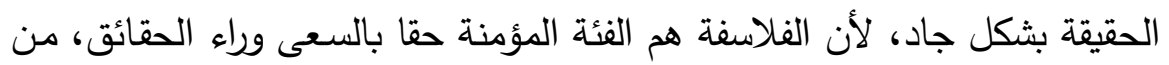

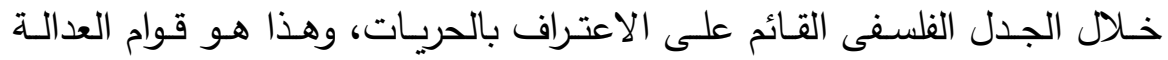
الحقيقيـة(00) وبرغم هذه الانتقادات من جانب هـامتون لتلك النظريـة إلا إنها تمتدح فيها إفساح المجال للنساء للوصول لزمام السلطة، حيث إن إن الجزء العاقل

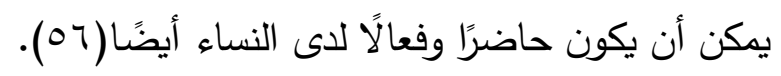
والحق أن لأفلاطون التميز في هذا الجانب ؛ فوضع المرأة في العصور القديمة

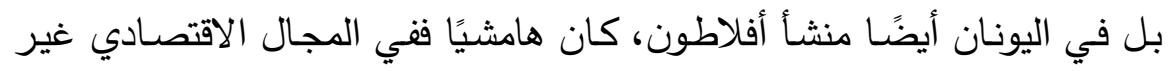
مسموح لها بممارسة المهن ومن الناحية الثقافية كانت محرومة من التعليم، وكذلك الك الكيان

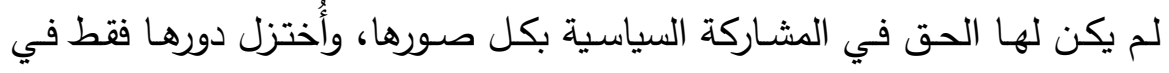

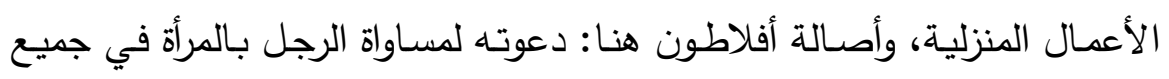

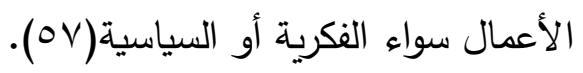

رابعاً: النظرية المستندة إلى الموافقة the consent-based theory (العقد (the social contract الاجتهماعي

يرسم التعاقد حياة بدون حكومـة، حياة طبيعية تعاني من الصـراع سواء في

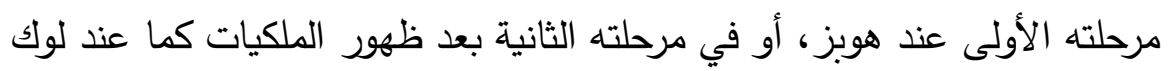

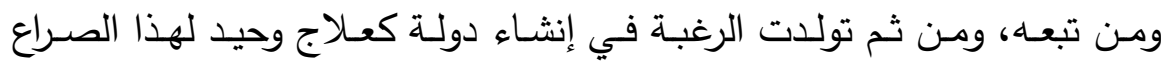

(55) Hampton, Jean.should Political Philosophy be done Without Metaphysics? Ethics, No. 99, The University of Chicago, (July1989), pp. 809,813

(56) Political Philosophy, p. 25

$$
\begin{aligned}
& \text { (OV) فؤاد زكريا: المرجع السابق، ص } 1.0 \text {. } \\
& (r \cdot r)
\end{aligned}
$$




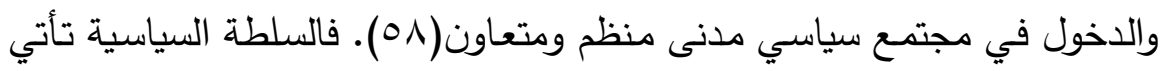
من الموافقة الشرعية للشعب من خـلال عقد اجتماعي، وهذا العقد لا يخرج في شكله عن طريقتين: - من

الأولى: عن طريق تعاقد مباشر بين الناس والحاكم، سواء تعاقد كل فرد بشكل منفصل مـع الحاكم، أو تعاقد الحاكم مـع الناس كمجموعة واحدة كمـا هو الحال عند لوك وروسو. والثانية: التعاقد على السلطة بطريقة غير مباشرة، عن طريق عقد بين النـاس مع بعضهم بعضـا لاختيار ممثل السلطة، بحيث لا يكون هذا

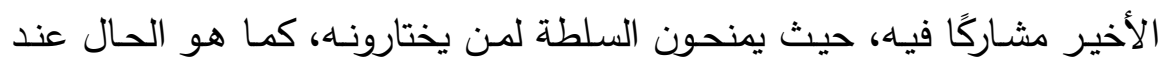
هوبز • وتطلق هامتون على الطريقة الأولى من التعاقد: العقد الاجتماعي للوكالة (the agency social contract)، حيث يمنح الثعب السلطة للحاكم ويحتفظ بالحق في أخذها إذا أخل بمضـمون التعاقد؛ فالثـعب هنا يمنح السلطة للحـاكم كقرض من الممكن استرداده، وهذا يعطي للشعب الحق في الثورة أو التمرد ضد the (الحاكم، أما الطريقة الثانية من التعاقد فتطلق عليها العقد الاجتماعي للإبعاد (alienation social contract )، حيث يمنح الشعب السلطة للحاكم كمنحة لا رجعـة فيها، وبالتالي يكون التمرد أو الثورة ضـد الحـاكم أمـراً غير شرعي.(ه)

(58) The Contractarian Explanation of the State, p. 246

تحل نظرية العقد الإجتماعى العلاقات المدنية محل العلاقات الطبيعية، وهى من أهم النظريات

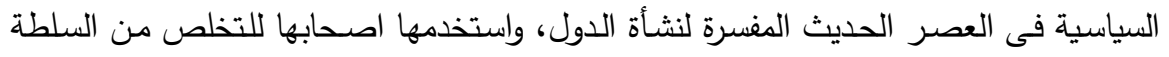

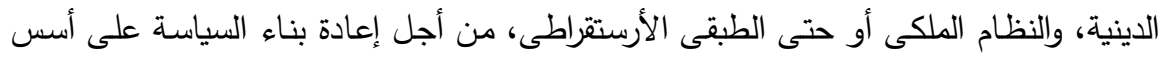

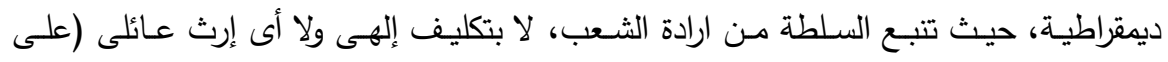

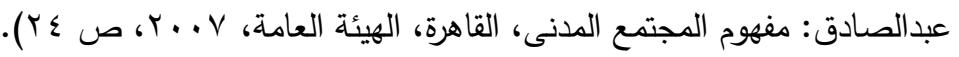
(59) Political Philosophy, pp. 40, 41

$$
(r \cdot r)
$$


وهذا التتظير التعاقدي لتأسيس السلطة ونثـأة الدول هو بدايـة لفهم كيف تم الارتباط بين البشر قديمًا (· ج).

واللافت للانتبـاه أن هـامتون في تحليلها لجذور هذه النظريـة لا تعود بهـا

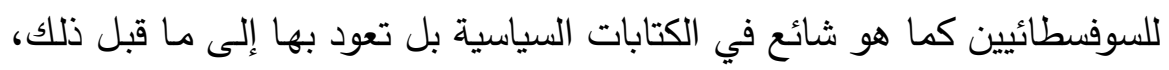
حيث كتاب المسرحيات مثل أرستوفانيس (من رواد المسرح الساخر في اليونان

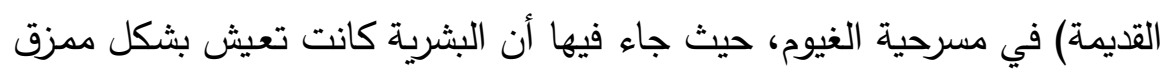

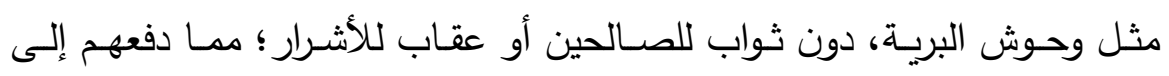

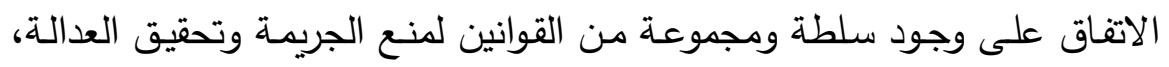
وهذا قد تحقق بالفعل وتم تنظيم المجتمع. وقد اقترح أفلاطون في محاوراته أفكارًا

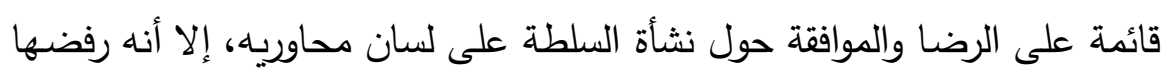

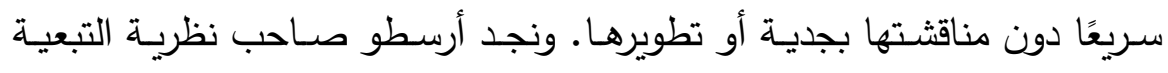

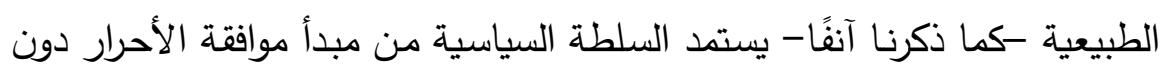

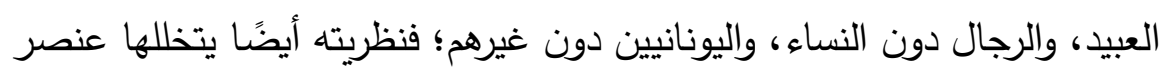

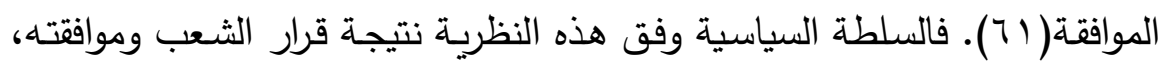

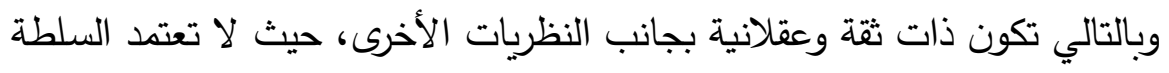

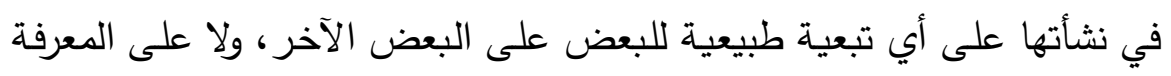

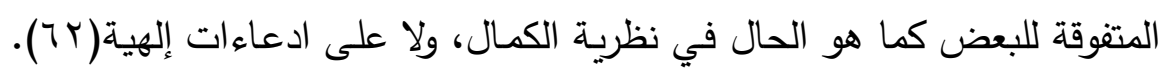

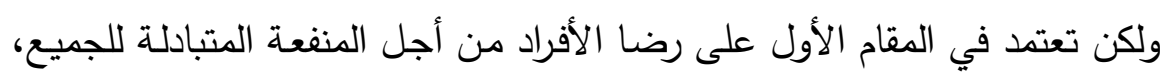

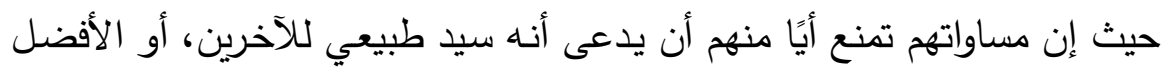

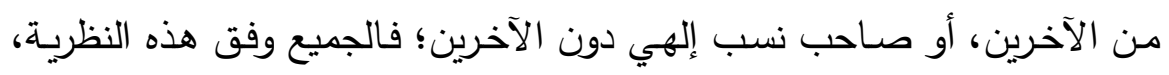

(60) The Intrinsic Worth of Persons, p. 38

(61) Political Philosophy, pp. 31, 32

(62) Political Philosophy, p. 28

$$
(r \cdot \varepsilon)
$$


يعملون معًا لاتخاذ أفضل القرارات السياسية(بآ). فالسلطة هنا خُلقت من قبل

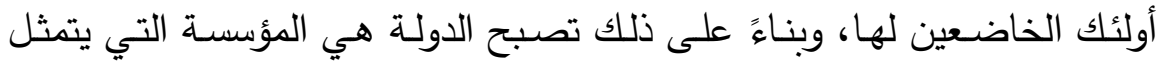

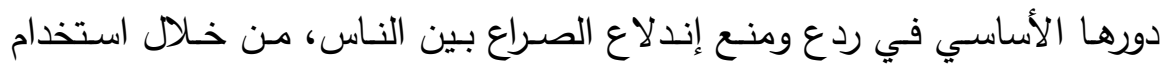
المشرعين والقضاة والقائمين على التتفيذ، ويتم الحفاظ عليها بموجب اتفاقية يكون فيها الناس موافقين على ما ستفعله حكومتهم( ؟7). وتتتقد هامتون نظرية الموافقة هذه بشقيها سواء الموافقة عن طريق الإبعاد (العقد الاجتماعي للإبعاد) كما هو

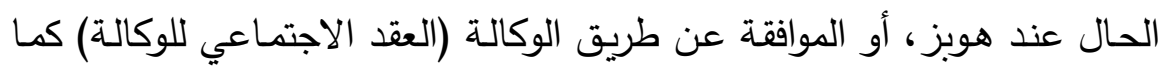
هو الحال عند لوك ومن تبعه على النحو التالي:

أولا: نقد نظرية العقد الاجتماعي للإبعاد (the alienation social contract) هذا الثكل من التعاقد يقوم على إبعاد الحاكم من المشاركة في العقد أو الإلتزام

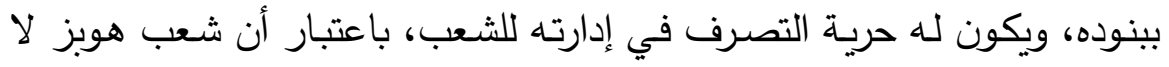
يصلح معه إلا هذا النظام من الحكم المطلق المستبد، حيث إنه يعيش في حالة الدالة

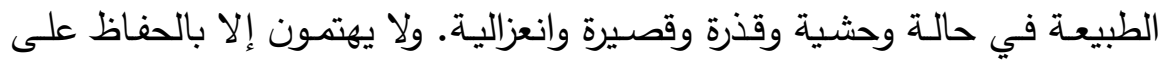
أنفسهم وتحقيق مصـالحهم الذاتية بالإضـافة إلى رغبتهم في المجد والثناء؛ مما

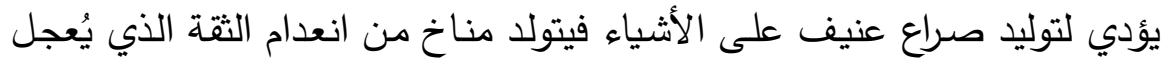
بمزيد من العنف والدمار ، ومن ثم فلا مفر من وجود سلطة سياسية مستبدة ومطلقة كثرط ضروري لإحلال السلام، ومن ثم فلا مفر من نقل الحقوق الفردية برُمتها من الثعب إلى الحاكم دون قيد أو شرط، وهذا هو طبيعة الالتزام التعاقدي

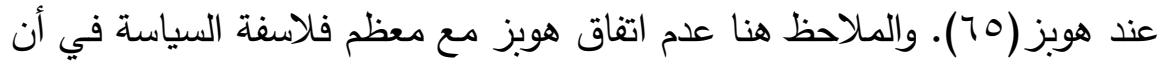

(63) The Intrinsic Worth of Persons, p. 276

(64) The Intrinsic Worth of Persons, p. 207

(65) The Contractarian Explanation of the State, p. 346

$$
(r .0)
$$




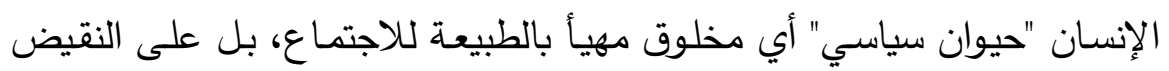

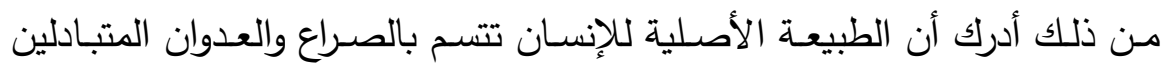

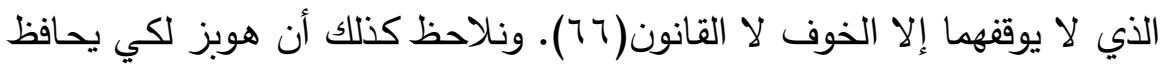

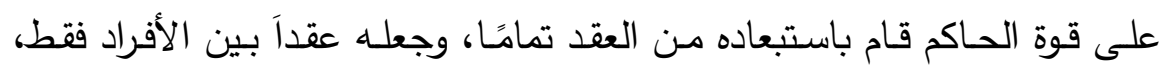

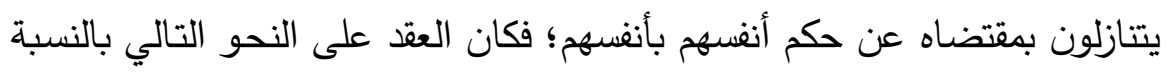

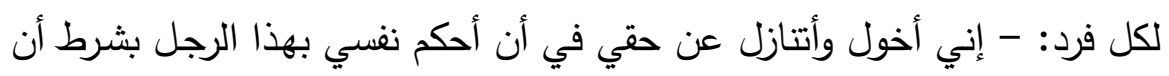

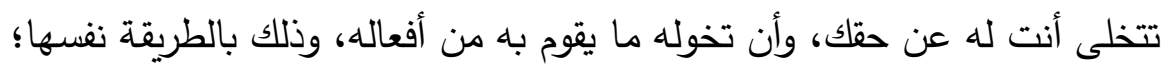

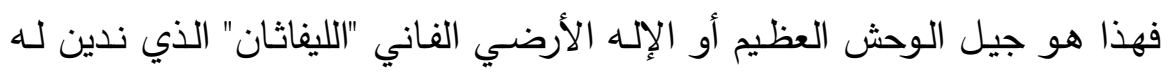

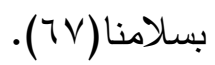

وترى هامتون أنه حسب هذا الوصف لطبيعة شعب هوبز فإن السلوك العدواني

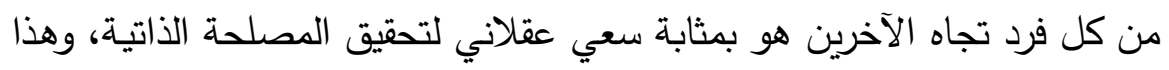

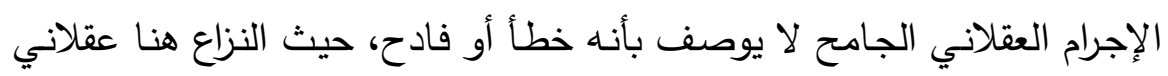

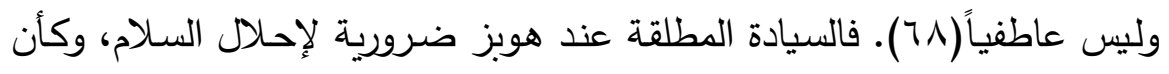

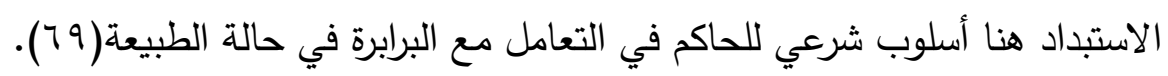

حول وصف هوبز لحالة الطبيعة راجع بالتفصيل: هوبز : اللفياثان، ترجمة. ديانا حبيب حرب،

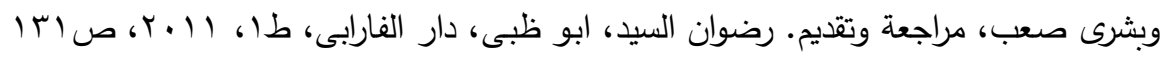
وما بعدها

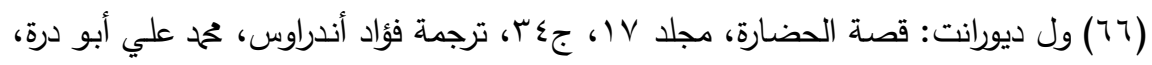

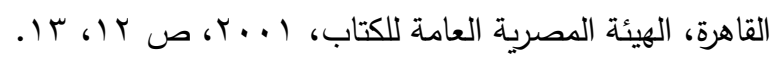

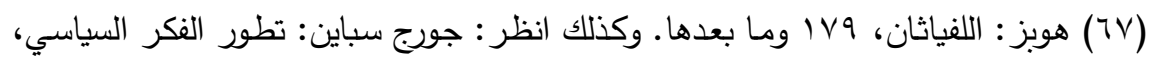
الكتاب الثالث، ترجمة: د/راشد البراوي، تقديم د. أحمد سويلم العمري، القاهرة، الهيئة الهصرية

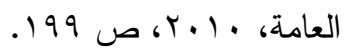

(68) Hobbes And The social Contract Tradition, p. 63

(69) Hobbes And The social Contract Tradition, pp. 10, 253

$$
(r+r)
$$


والعقد الاجتماعي بهذا الشكل عبارة عن بنية معقدة، حيثُ إن الاتفاق المتبادل بين الأفراد لتأسيس السلطة السياسية ليس في الواقع اتفاقاً واحداً، ولكنها مجموعة من الاتفاقيات الثنائية التي تربط كل طرف بالطرف الآخر ، وفي كل اتفاقية ثنائية يتخلى كل فرد عن حقه في الحكم الذاتي، ثم يتم اختيار السيادة الفعلية في نهاية المطاف بعد انضـمام الأطراف إلى اتحـاد جماعي عن طريق تداخل الاتفاقيات المتبادلة( • V). وترفض هامتون هذا التعاقد كمبرر لنشأة الدولة لأسباب جديرة أن

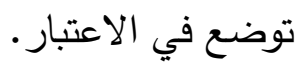

ا - مشكلة الاتحاد بين الحاكم والدولة؛ فمن المعروف أن الدولة مؤسسـة ذات

هيكل محدد ومنظم، أما الحكام فهم الذين يشغلون المناصب داخل الدولة، ومن ثم يكون الخضـوع السياسـي للحاكم هنـا هو الخضـوع لسيادة القـانون ولبيس للحساكم كثخص(V) أما النظام عند هوبز فلا نجد فيه هذا التمييز، حيث الحاكم هو

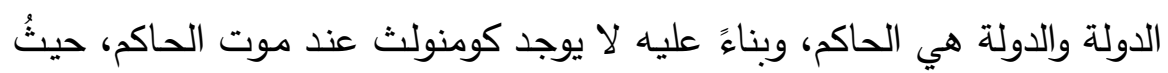
يذوب بوفاته؛ مما يؤدي إلى العودة إلى حالة الإرتباك الأولي، وحرب الجميع ضد

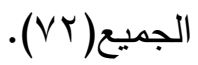

r- إذا كان شـعب هوبز في حالـة الطبيعـة بهذا الوصف الدموي الوحشي، حيث لا يوجد قانون وضعي لتنظيم تلك العلاقات؛ فكيف وهم بهذه الحالة يكونون قادرين على إتمام عقود بهذا الشكل المعقد -كما أشرنا سالفًا- الذي يشتمل على قدرة كل طرف في العقد على ربط نفسه بالعمل العقلاني الجماعي، بحيث يكون على اعتقاد يقيني بأن الطرف الآخر سيلتزم بهذا الإجراء المتفق عليه؛ فنحن هنا في نطاق ما يطلق عليه مشكلة السجينين، حيث لا يوجد أمن لأداء العقد من كلا

(70) The Intrinsic Worth of Persons, pp. 194

(71) Hobbes And The social Contract Tradition, p. 25

(72) Hobbes And The social Contract Tradition, p. 130

$$
(r \cdot v)
$$


الطـرفين(VT). وبنـاءً على ذلك يضـــى الإجـراء الجمـاعي التعاوني المطلوب

لإحلال السلام مستحيلا بالنسبة للأشخاص في حالة الطبيعة(V ع V).

r- إذا كان كل فرد في حالة الطبيعة يغلب مصـالحه الذاتيـة على مصـالح

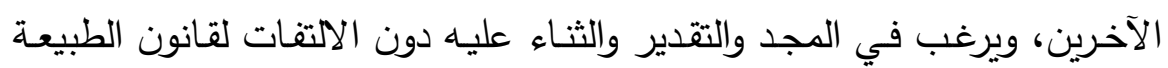

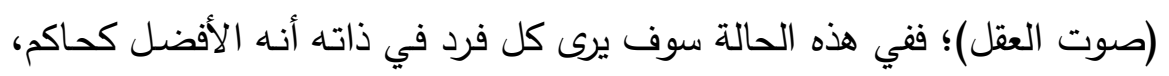

ومن ثم سوف يقوم بعملية تصويت على ذاته مما يؤدي إلى حالة من الجمود،

ولن تتحل المشكلة وستظل حالة الطبيعة كما هي(vo).

ع- إذا كـان لا يمكن تحقيق السـلام عندـ هـوبز إلا إذا كـان الحساكم يمتلك

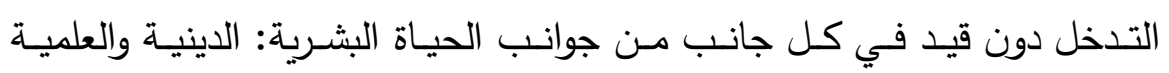

والاقتصادية والاجتماعية فبذلك يُصبح ثمن السلام عند هوبز هو تدمير الإرادة

الإنسانية بأكملها.

ه- لا يستطيح شعب هوبز وهو بهذه الصفات في حالة الطبيعة أن يتخلى

عن كل حقوقه للحاكم؛ فلا يوجد شخص عاقل يقبل وهو لهون الدخول كطرف في عقد بهذه

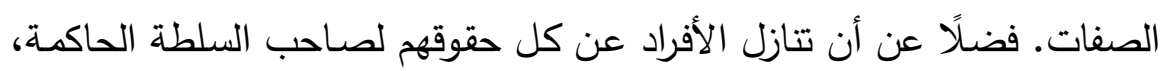

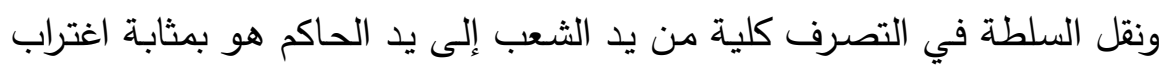

حقيقي للثخص المحكوم؛ فنقل السلطة هنا ليس تفويضًا بل تغريبًا (VT).

؟- غالبًا ما تؤدي مشكلة الملكية المطلقة إلى الوراثة في السلطة؛ فلا يعرف

الثعب من هو الخليفة في النظام الملكي المطلق(VV).

(73) The Intrinsic Worth of Persons, p. 193

(74) Hampton, Jean.can We Agree on Morals? Canadian Journal OF Philosophy, Vol. 18, No. 2, pp. 331-356, June 1988, p. 332

(75) Hobbes And The social Contract Tradition, pp. 162, 220

(76) Hobbes And The social Contract Tradition, pp. 220, 262

(77) Hobbes And The social Contract Tradition, p. 130

$$
(r \cdot \Lambda)
$$


V- على صحة هذا الفرض التعاقدي كمبرر لإنشاء السلطة السياسية؛ فكيف يلتزم الأحفاد بعقد الأجداد القدامى مع الحكام القدامى؛ فما لنا بهذا التعاقد، ولماذا

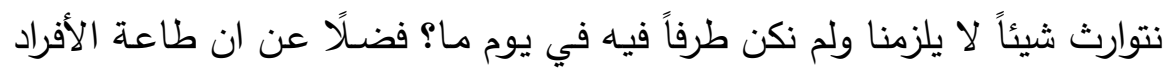

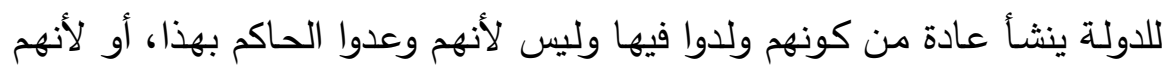
يحترمون ميراث الأجداد في التعاقد(V). والحق ورغم كل هذه الانتقادات الموجهة لهوبز إلا أننا يجب عند تتييم فكر ما أن نضعه في سياقه التاريخي؛ فقد أراد هوبز من وراء هذا العقد إعادة بناء الدولة

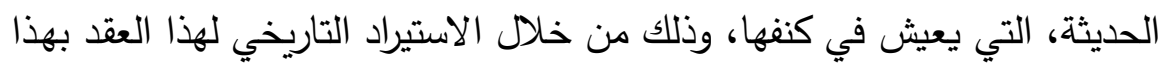

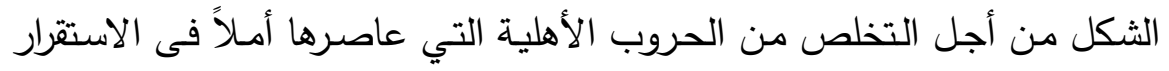

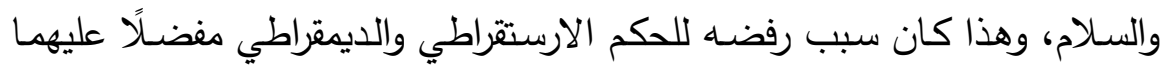

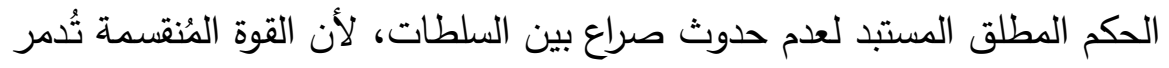
بعضها البعض كما حدث بالفعل في زمن هوبز ، حيث الصـراع بين البرلمـان

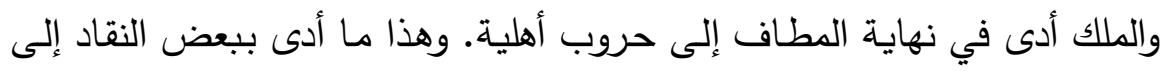
القول بأن هوبز أحال الواقع السياسي ببلاده إلى نظريـة فلسفية، ولكن لـ لم يتابعها الانجليز فى زعمه هذا، بل على العكس فقد عبرت الديمقراطية البحار من انجلترا

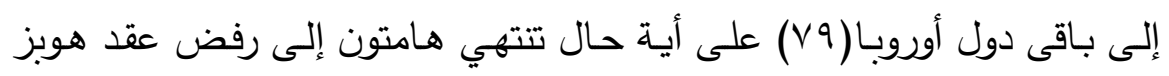

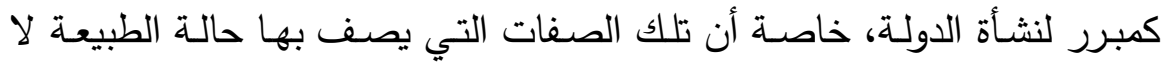
تؤدي إلى النتيجة السياسية التي يقول بها، وهي إبرام عقد اجتماعي، ومن جانب آخر كيف يكون الناس عقلانيين بما فيه الكفاية لإنشاء تلك السلطة بهذا العقد

(78) The Intrinsic Worth of Persons, p. 203

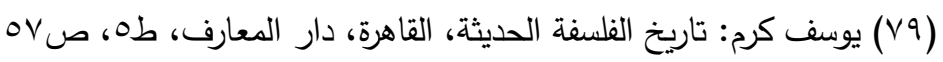

$$
(r \cdot q)
$$


المركب والمعقد، وفي نفس الوقت غير قادرين على العيش بشكل تعاوني وسلمي

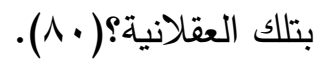

ثانيًا- نظرية العقد الاجتماعي للوكالة (the agency social contract)( (1)): هذه الصورة تتظر إلى الناس في حالة الطبيعة بشكل أكثر تفاؤلاً بـدًا من الصورة السالفة الذكر الذي يغلب عليها التشاؤم الهوبزي؛ فالناس هنا يتصرفون

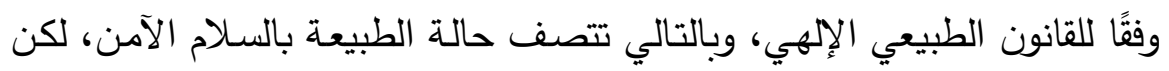

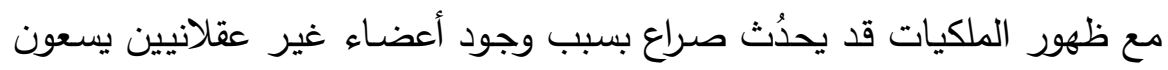

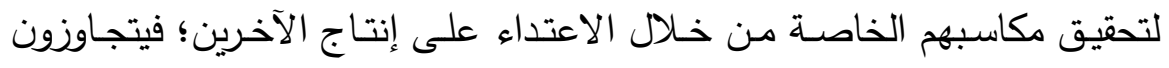
بذلك قانون الطبيعة ليعيشوا وفق قانون آخر ، أو قد يفشل البعض (بسبب التحيز

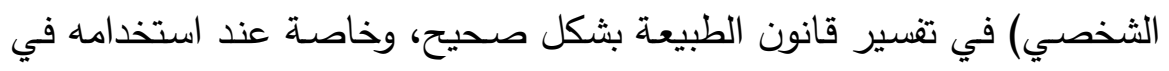

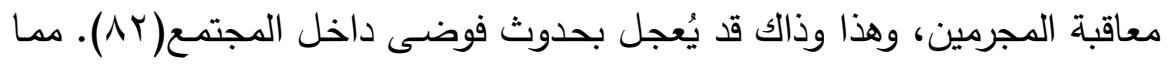

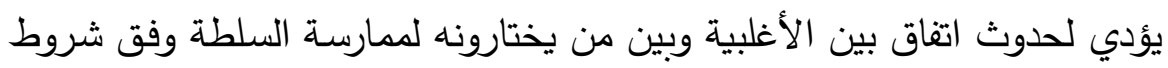

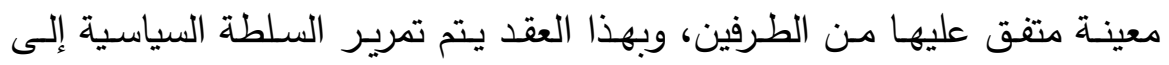

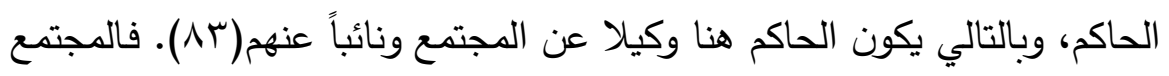

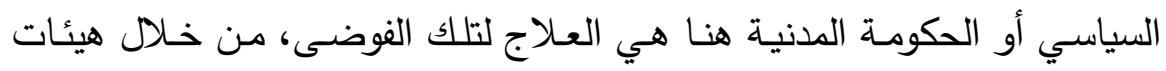

(80) Hobbes And The social Contract Tradition, p. 85

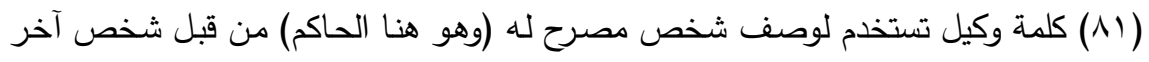

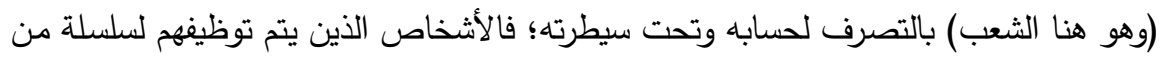

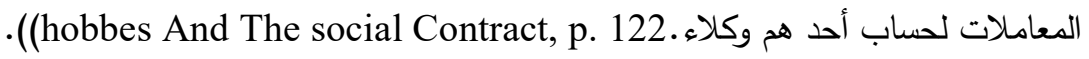

(82) The Intrinsic Worth of Persons, p. 191

حول توصيف لوك لحالة الطبيعة بالتفصيل، راجع: جون لوك: في الدكم الدنىى، ترجمة. ماجد

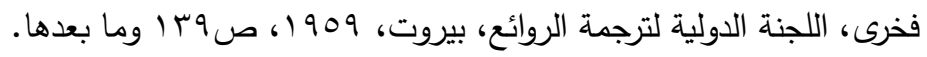

(83) The Contractarian Explanation of the State, p. 360

$$
(r) \text {. }
$$


محايدة تفسر وتطبق قانون الطبيعة بشكل صحيح، وتتحلى بالنزاهة والموضوعية في الفصل في المنازعات باستخدام ذلك القانون(ء^). فالسلطة السياسية هنا لم تأت لمصالح ذاتية فحسب بل لدوافع دينية وأخلاقية كذلك(1)). وهذا يعني- كما تقول هامتون - أن فكرة الوكالة هذه تخضـع للإثراف المستمر من جهة الثعب على الوكيل (الحاكم) الذي ينوب عنهم وتتسم هذه العلاقة بالخضوع المستمر من جهة الوكيل للشعب، وعلى الوكيل أن يظهر قبوله لهذه العلاقة بشكل صريح أو لوه

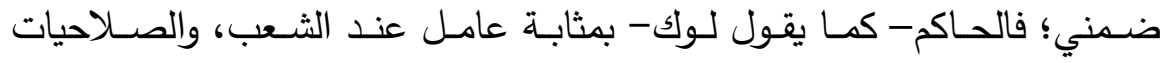
الممنوحـة لـه مقيدة ببعض الواجبات التي تحقق السـعادة للشـعب، والسيادة هنـا مرتبطة في وجودها بمراقبة الرعايا(؟1). ومفهوم الوكالة هذا لا يمنح الحاكم حق التـدخل فـي كـل أمـور رعايــاه- بخـلاف هـوبز - كالثـئون الدينيـة والمصــالح

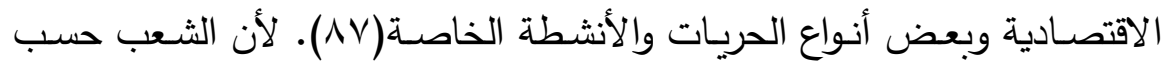
هذه النظرية لا يتنازل عن كل حقوقه- كما قال هوبز - بل بعض حقوقه الطبيعية لكي يكتسبها بشكل مدني من أجل حفظ المجتمع وسـلامته. ووفق هذا المفهوم (الوكالة) يتم الحفاظ على سيادة القانون واستقلاله عن السلطة التنفيذية(^^).

وتتقد هامتون العقد الاجتماعي للوكالة أيضًا رغم أن الحاكم مقيد بتعاقد مـع الشعب فترى: أن خضوع الشعب للحاكم وفق هذا العقد غير موجود لأن الثعب هو القاضي النهائي لآداء الحاكم، حيث إن الثعب هو الذي يتحكم في تصرفات الوكيل، والإشراف عليها بالكامل، ويحق لهم إلغاء التوكيل متى أرادوا ذلك، إلا أن الخـلاف الحتمي بين الأشخاص تجـاه أعمال السلطة السياسية لابد من ظهوره

(84) The Intrinsic Worth of Persons, p. 191

(85) The Contractarian Explanation of the State, p349

(86) The Contractarian Explanation of the State, p. 360

(87) Hobbes And The social Contract Tradition, p. 25

(88) Dagger, Richard. "Jean Hampton's Theory of Punishment", p. 8 حول فكرة العقد وتوصيفه عند لوك :راجع/ لوك: فى الحكم المدنى، ص 80 الو 190 وما بعدها. 


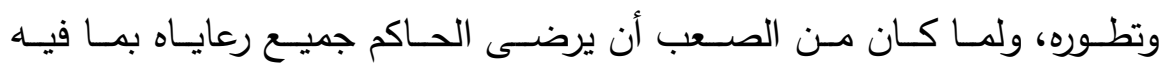
الكفاية(1). فإن هذا سوف يؤدى بثكل مستمر إلى الفوضى وعدم الاستقرار

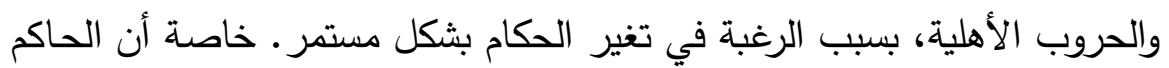

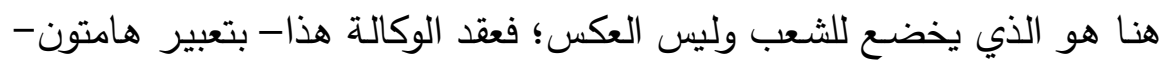

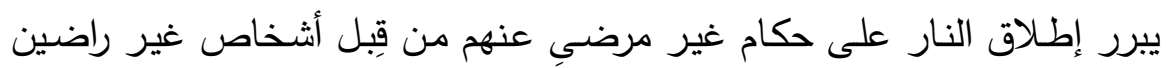
عن عمل الحاكم، خاصة إذا استبد ورفض التتازل عن السلطة الموكلة إليه. هذا

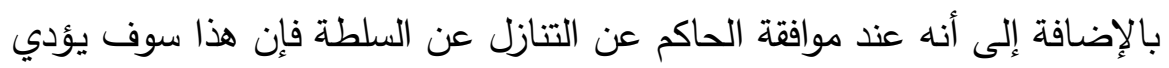
باستمرار إلى تغير الحكام بشكل يؤدي إلى عدم استقرار الدولة( • 9).

وقد لا نجانب الصواب لو قلنا: إن هذا التخوف من هامتون تجاه تللك النظرية قد تحقق بالفعل ولاحظناه فى ثورات الربيع العربي، حيث إن الاستخدام الخاطئ

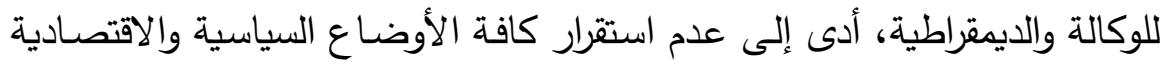

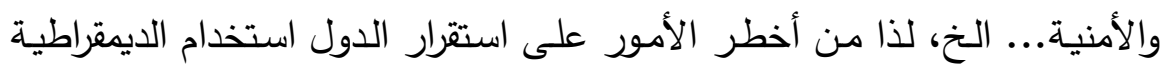

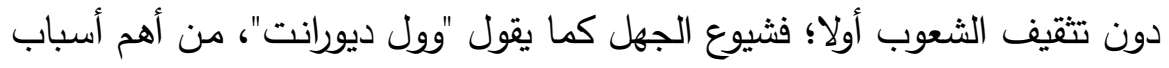
إخفاق الديمقراطية؛ فبلاهة الجمهور داعية بشكل حتمى لظهور الإستبداد بقوته

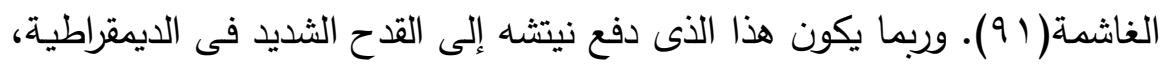

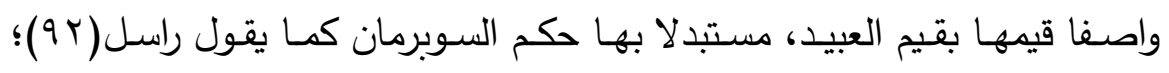

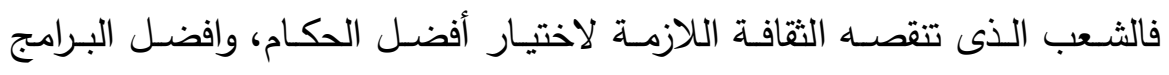

(89) Hobbes And The social Contract Tradition،, pp. 124, 221

(90) Political Philosophy, p. 63.

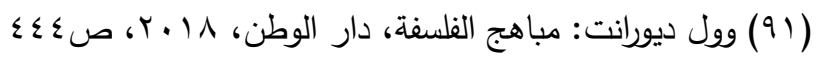

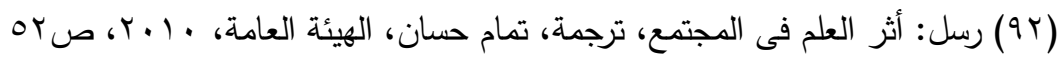


السياسية، لا ينبغى استخدام الديمقراطية فى سياسته، إلا بعد الإعداد الكافى لله

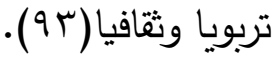

وبالإضـافة لنقد هامتون لعقد هوبز ولوك تعود فتتقد نظريـة العقد الاجتمـاعي بثكل عام، أي أن انتقادها موجه لكل صور العقد الاجتماعي فترى: - أن تحليل العقد الاجتماعي التقليدي يفترض أن كل فرد يمتلك سلطة الحكم بنفسه في حالة الطبيعـة والتي يمنحها للحساكم مـن خـلال التعاقد، وهذا بـدوره سوف يؤدي إلى إشكالية تتمثل في وضـعية الأقليـة الرافضــة لهذا التعاقد والخـارجين عنـه؛ فمـن

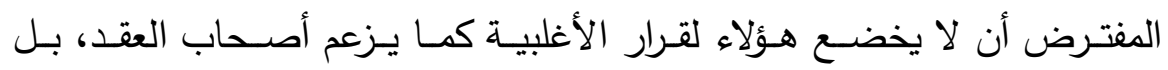
المفترض هنا أن النظام السياسي سيكون له سلطة فقط على من كانوا طرفًا في العقد، وهذا بدوره سوف يمثل مشكلة للسلطة التي تعتقد أن سلطتها تكون على الإقليم بما فيه، وليس فقط على من منحوها السلطة بالتعاقد( ؟ 9). وإذا قلنا مـع

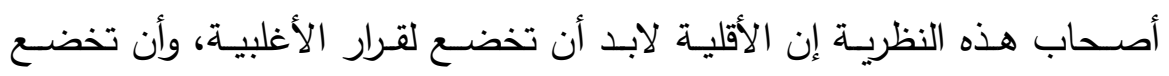
لقـرارات السـلطة السياسـية؛ فلمـاذا لا يكـون للأقليـة الرافضــة للتعاقد الحريـة في الحي الخروج بأرضهم وجميع ممتلكاتهم الأخرى وحرياتهم من هذا التعاقد. وكيف يمكن تبرير نظام سياسي تبريرًا أخلاقيًا وهناك إناس في أرضـه رافضون لـه، ورافضون

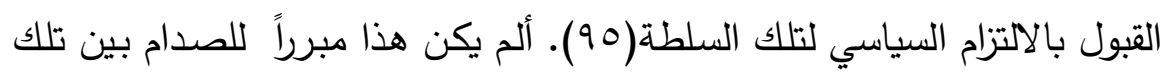
الأقلية من جانب وبين السلطة والمتعاقدين معها من جانب آخر؟ ومن ثم تتتهى هامتون إلى أن فكرة العقد هذه لا تقدم تفسيراً دقيقاً لنشأة وأصل كل دولة بشكل دقيق، أو كما يقول هيوم بامتعاض: هل جميع الناس في جميع الأزمان وافقوا على سلطة حكامهم، أو وعدوهم بطاعتهم(7 97).

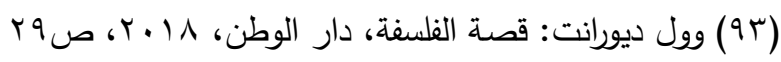

(94) Political Philosophy, p. 97.

(95) Political Philosophy, pp. 61, 98.

(96) The Contractarian Explanation of the State, p, 344 


\section{المبثث الثالث}

\section{نظرية هاهتون في اختراع السلطة}

The invention of political authority

من خلال ما سبق تبين لنا رفض هامتون لنظريات تفسير نثأة الدولة الأربعة

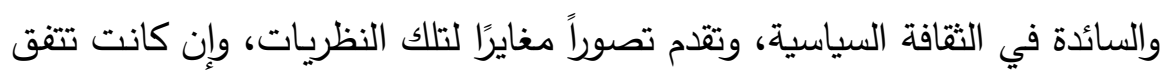
معهم في وصف حالة الطبيعة الذي كان سبباً في خلق الدولة واختراعها. فحالة الطبيعة حسب تصورها مليئة بالسلوك المعادي للمجتمع والنظام والذي ينتج عن لن النيان عاطفـة حب الذات، والعنف الذي يظهـر نتيجـة أشـكال مختلفـة مـن الرذيلـة، والاضطرابات التي تتشأ عندما يتصرف الناس بشكل غير عقلاني، ووسط حالة

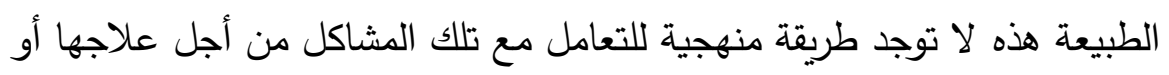

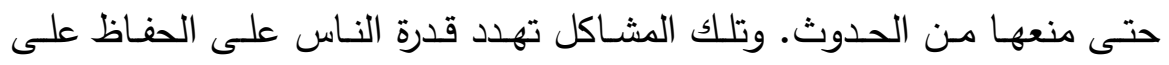
حياتهم، وتجعل التعاون البشري مستحيلا؛ مما يمنع من التفاعل المتبادل لجميع

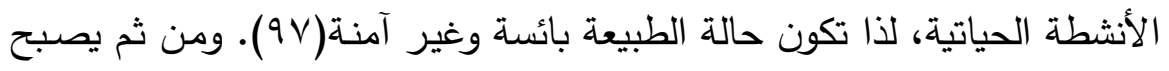

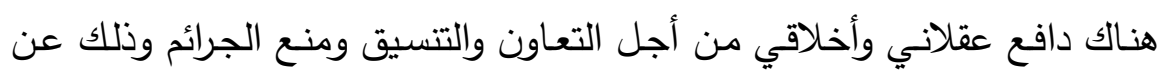

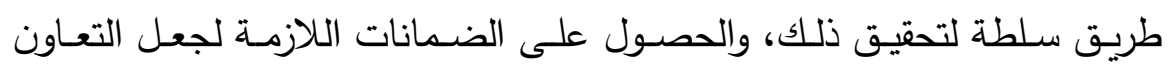

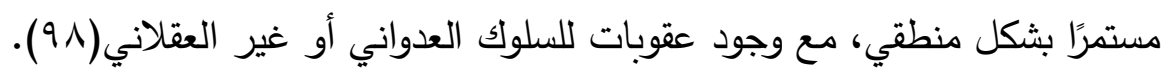
وذلك من خلال القانون المستمد من العقل، لأن القوانين ضرورية لردع الخارجين من خلال العقوبات السلبية(99). (9).

(97) Political Philosophy, p. 72.

(98) Political Philosophy, p. 74.

(99) The Intrinsic Worth of Persons, Contractarianism in Moral and Political Philosophy, p. 104. 
وحول كيفية نثأة السلطة السياسية هذه، ترفض هامتون فكرة تتازل الأفراد عن كل حقوقهم من خلال عقد اجتماعي كما هو الحال عند هوبز ، أو حتى التنازل عن بعض حقوقهم كما هو الحال عند لوك وروسو، حيث إن فكرة التعاقد هذه تقوم على افتراض تتازل المجتمع الطبيعي عن سلطتهم في المعاقبة إلى حاكم مدني ليقوم بتلك الوظيفة وهذا ما ترفضه هامتون بشكل قطعي. فالسلطة السياسية

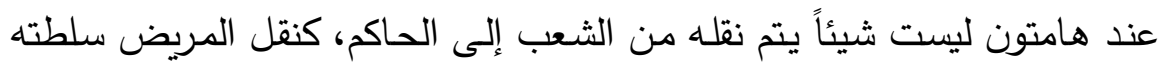
في العلاج إلى الطبيب، حيث إن تلك السلطة لا تكمن بالفطرة في كل فرد بحيث

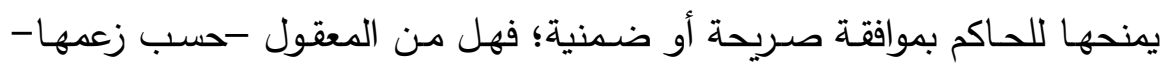
الاعتقاد بأن السلطة السياسية التي يمارسها الحاكم لمعاقبة الجناة في الداخل وتسيير الثئون الخارجية هي شيء يملكه كل فرد في حالة الطبيعة! وهل كل شخص في حالة الطبيعة يمتلك بثكل طبيعي الحق في استخدام أي إجراء فعلي

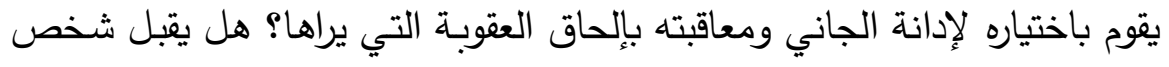
في حالة الطبيعة من شخص آخر أن يقوم بهذه الإجراءات تجاهـه؟ ففي هذه بـانه الحالة ستكون الإجراءات والعقوبات وحشية ومُهينة ومفتقرة إلى الحياد والمساواة

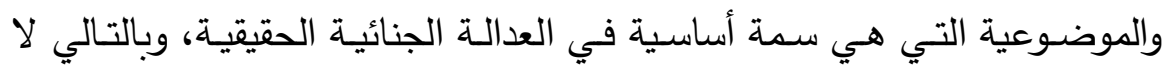
يقبلها شخص في حالة الطبيعة( . (1). وبناءً عليه فالسلطة التي تدير نظام العدالة ليست موجودة بكل شخص ليتنازل

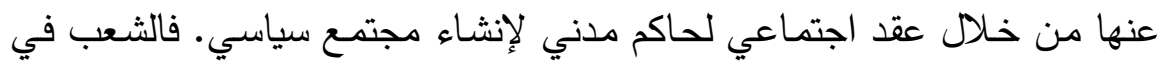

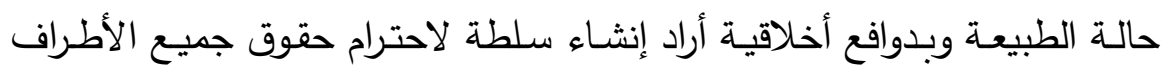
بإنصاف ونزاهة؛ فتم إنثاؤها من قبيل مجموعة من الأشخاص الذين ينظرون إليها

(100) Political Philosophy, p. 76.

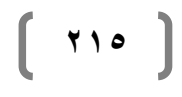


على أنها حل لمشاكل الفوضى. فالسلطة هنا عملية اختراع وليست تعاقداً أو اتفاقاً

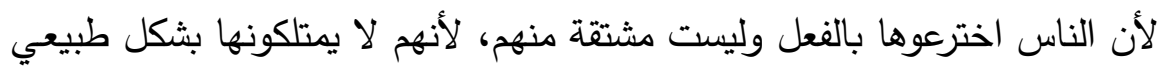
كما يزعم فلاسفة العقد،. فالدولـة الحقيقية لا يتم إنشاؤها من خـلال وعود بين

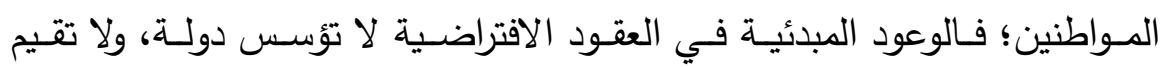

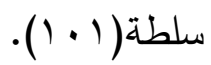

أما الاتفاق فيكون حول الهيكل الاجتماعي المطلوب والأشخاص القادرين على

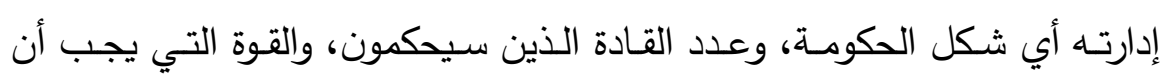

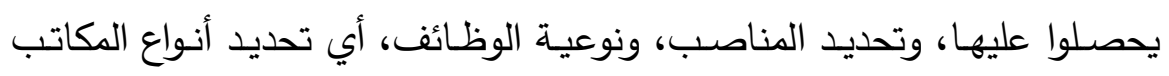
داخل الحكومة، ومدى السلطة التي يجب أن يمتلكها كل صاحب مكتب، وتحطب، وتحديد

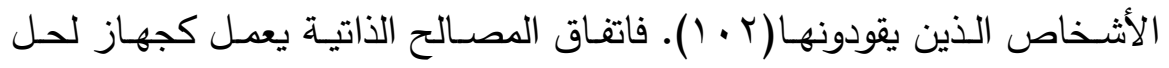

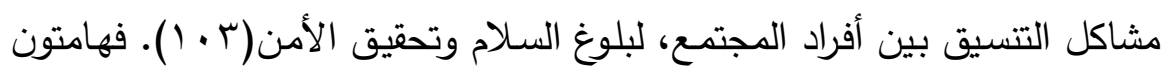
هنا تستبدل الحديث عن العقود بالحديث عن الاتفاقيات والعلاقة بين الوكالات

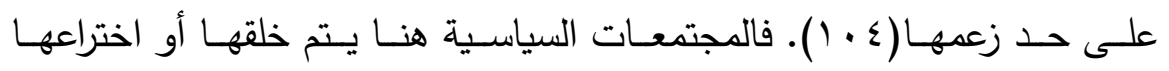
وصيانتها، وهذه العملية تنطوي على مجموعة من المعايير الرسمية التي تحدد النظام القانوني والتزامات المسئولية الذين يعملون في إطاره، تمامًا كما يحدث في لئي الديمقراطيات الحديثة(0 • ( ).

وتضــع هـامتون مجموعـة مـن الآليـات الهامـة، لاستقرار النظــام السياسـي،

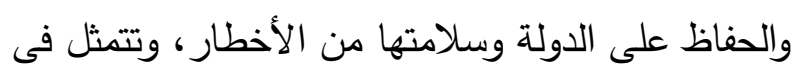

(101) Political Philosophy, pp. 76, 78

(102) Can We Agree on Morals?p. 350

(103) Hobbes And The social Contract Tradition, pp. 142, 147

(104) The Intrinsic Worth of Persons, p. 211

(105) Political Philosophy, p. 105. 
1- تحديد القضايا التى يحق للحاكم التدخل فيها، أى التى يكون له فيها ولاية قضائية، من أجل تحديد مجالات قرار السلطة

$$
\text { r- تحديد الغرض من ممارسة السلطة فى المجتمع }
$$

س- بناء الهيكل السياسي الذى يتم من خلالـه ممارسـة السلطة، واختيار شكله

$$
\text { المناسب (ملكى/أوليجاركى/ديمقراطى... إلخ)( ( - (). }
$$

ع- تحقيق العدالة السياسية: فالمجتمع السياسي يجب أن يكون عـادلا، من

خلال تحقيق الحريـة والمساواة لجميع المواطنين(v • ()، لأنهما أساسيات بديهية كامنة فى الثقافة السياسية للمجتمعات الديمقراطيـة الحديثة(1 • ( ) مـع استخدام القوة العادلة لسيادة العدل؛ فالعدل يتطلب دائمـا القوة لمعاقبـة السلوك الإجرامى المخالف للقوانين(9 • ( ) .

0- ت تثقيـف المجـرمين ثقافـة أخلاقيــة؛ فيمــا يخـص السـلوك الإجرامـى اللأخلاقى؛ فجميع المجرمين فى حاجة للحقوق الذاتية التى على الدولة أن تكفلها لهم، وفى مقدمتها دعم التثقيف الأخلاقى، بأفضـل الطرق الممكنة؛ فضـلًا عن تثقيف المجتمع كذلك كوقايـة من فعل السلوك الـلا أخلاقى، لكى تكون ادانتهم على السلوك الاجرامى مبررا اخلاقيا؛ فعقاب الله لأدم وحواء ليس بسبب أكلهما

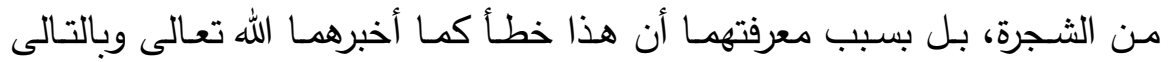
صارت المعرفة سبب الإدانة( • (1).

(106) Political Philosophy, p. 75.

(107) The Intrinsic Worth of Persons, p. 156.

(108) Should Political Philosophy be done Without Metaphysics? p.796. (109) Can We Agree on Morals? p. 332.

(110) The Intrinsic Worth of Persons, p. 89.

$$
(r) v)
$$




\section{الخاتمة}

تبين لنا من خلال دراسة هامتون لنقدها لنظريات السلطة، قدرتها على التحليل والنقد لتلك النظريات، حيث استطاعت بمنهجها النقدى كثف عيوب تلك النظريات وعدم قدرتها على تبريرها لنشأة السلطة فى المجتمع، مع تقديمها لنظرية تدور حول خلق السلطة واختراعها، وقد استطاع البحث من خلال تلك الدراسة

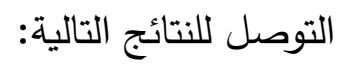

1- ليست كل سيطرة سيادية من جهة الحاكم على شعبه تعتبر مشروعة؛ فالسيطرة المشروعة هى تلك التى تحتوى بداخلها على مشروعيتها الأخلاقية، ץ- عدم صلاحية مبررات نظريات السلطة الدينية، وذلك لقيامها على أسس ميتافيزيقية؛ فلا يمكن التأكد منها بشكل عقلانى أو تجريبي.

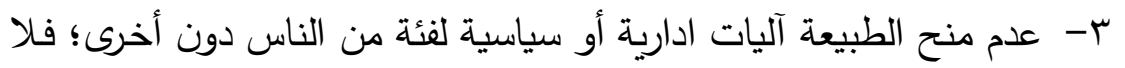

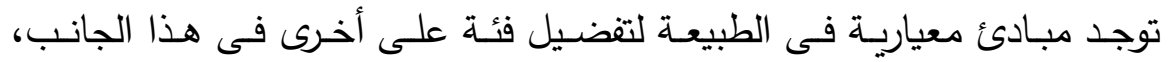
ومهارات البعض فى مجال ما ليس مبررا لتملكهم زمام السلطة، وهذ بدوره يقضى فلئي

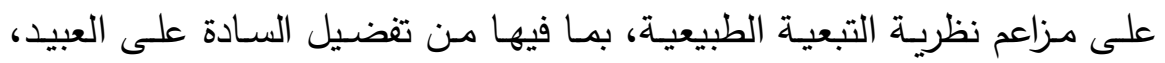
والرجال على النساء، والبيض على السود ع- تناقض نظرية الحاكم الفيلسوف المهيمن مع المبادئء العقلية، والفلسفة

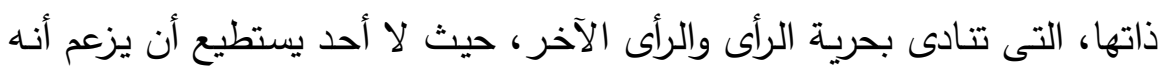
يمتلك الحقيقة دون غيره. 0- احتواء نظريـة العقد الاجتمـاعى للابعـاد على تتـاقض داخلى؛ فصفات شعب هوبز الفوضوى لا تؤدى للنتيجة المطلوبة ألاوهى تأسيس دولة منظمة.

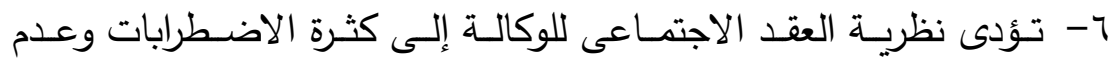
الاستقرار ، بسبب تغير الحكام بثكل مستمر، حيث الثعب هو الحاكم والحاكم هو الأها

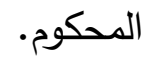




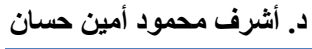

المنهج النقدى عند "جين هامتون" دراسة فى نثأة السلطة

مجلة وادى النيل للاراسات والبحوث الإنسانية والاجتماعية و التربوية

V- استخدام الايمقراطية مـع الثعوب غير المؤهلة ثقافيا لثقافة الديمقراطية،

سوف يؤدى حتما لانهيار الدولة وخرابها فى أقصر وقت.

^- ربط الديمقراطية أو الهوية السياسية للدولة بالحركة النسائية فيها؛ فاستبعاد

المرأة مـن المجـال السياسـي بمثابـة جريمـة أخلاقيـة تتــافى مـع قيم الديمقراطيـة

والتعددية.

9- مسئولية الدولة عن التثقيف الاخلاقى للمجرمين، لكى تكون المعرفة هى

سبب إدانتهم.

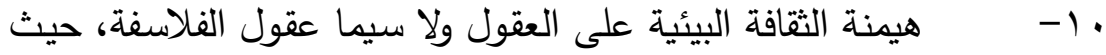

نجد انحناء أفلاطون وأرسطو أمام الأعراف السائدة فيما يختص بنظام العبيد، بل

وتبريره طبيعيا.

11- وقـوع جين هـامتون فـى بعض الأخطـاء التى انتقـدتها فى النظريـات

الأخـرى؛ فوفق نظريـة اختراع السـلطة مـا زالـت مشكلة الاقليـات الرافضــة لخلق

السلطة بهذا الثكل موجودة، وما زالت مشكلة قدرة الأفراد فى حالة الطبيعة على الطى

اختراع تلك النظرية بهذا الثكل العقلانى موجودة كذلك، إلا أن نجاح هامتون هنا فى رفضها وجود السلطة السياسية داخل كل فرد فى حالة الطبيعية.

\section{قائمة المراجع}

مؤلفات جين هامتون

1. Hampton, Jean.hobbes And The social Contract Tradition, Cambridge, 1986

2. Hampton, Jean.political Philosophy, U S A, by Westview Press, 1997

3. Hampton, Jean.the Intrinsic Worth of Persons, Contractarianism in Moral and Political Philosophy, Edited by Daniel Farnham, Cambridge, 2007

4. Hampton, Jean.the Authority of Reason.edited by Richard Healey, Cambridge, 1998 
5. Hampton, Jean.can We Agree on Morals? Canadian Journal OF Philosophy, Vol. 18, No. 2, June 1988, pp. 331-356

6. Hampton, Jean.should Political Philosophy be done Without Metaphysics? Ethics, No. 99, The University of Chicago. (July 1989): (pp. 791-814)

7. Hampton, Jean, etal.the Idea of Democracy.edited by David Coop, Jean Hampton, and John E.roemer, Cambridge, (1993), (pp: 292: 314)

8. Hampton, Jean.the Contractarian Explanation of the State, Midwest Studies In Philosophy, (No.xV) (1990) (pp. 344-371)

9. Hampton, Jean. "Forgiveness and Christianity" Forgiveness and Mercy.jeffrie G.murphy, and Jean Hampton, Cambridge, 1988

10. Hampton, Jean. "Forgiveness, Resentment and Hatred" Forgiveness and Mercy.jeffrie G.murphy, and Jean Hampton, Cambridge, 1988

11. Hampton, Jean. " The Retributive Idea " Forgiveness and Mercy, Jeffrie G.murphy, and Jean Hampton, Cambridge, 1988

12. Hampton, Jean. " The Moral Education Theory of Punishment", in Philosophy and Public Affairs., (Vol 13, no 3), (1984), (pp. 208-228)

\section{مراجع أجنبية}

13. Farnham, Daniel. " Introduction" The Intrinsic Worth of Persons, Contractarianism in Moral and Political Philosophy, Cambridge, 2007.

14. Dagger, Richard. "Jean Hampton's Theory of Punishment" a Critical Appreciation.aPA, Newsletter on Philosophy and Law, (Volume 10, no. 2) (Spring 2011) (pp. 6-11).

15. Annas, Julia.proceedings and Addresses of the American Philosophical Association, (Vol. 70, No. 2) (Nov., 1996), (pp. 191193), Published by: American Philosophical Association Stable URL:

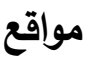

https://www.jstor.org/stable/3131051 Accessed: 14-11-2018 JSTOR -

http://wc.arizona.edu/papers/89/150/14_1_m.html

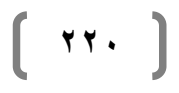




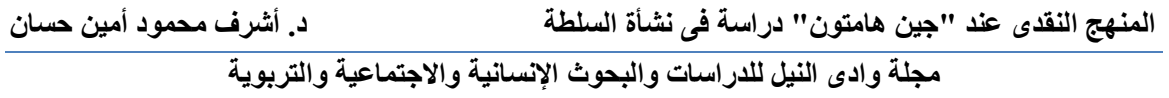

\section{المصادر والمراجع العربية}

ا. أرسطو : السياسـة، ترجمه من الإغريقية إلى الفرنسية بارتملي سـانتملير ،

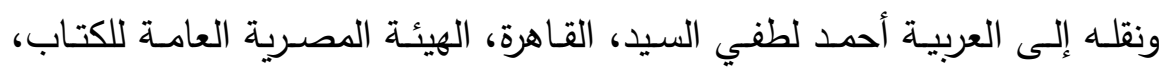
$\cdot r^{3} \cdot \hat{0}$

r. أرسطو: علم الأخلاق إلى نيقوماخوس، ترجمه من اليونانية إلى الفرنسية،

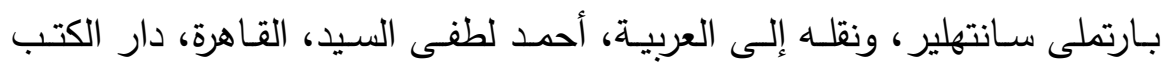

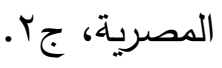

r. إسـاعيل زروخي: دراسـات فى الفلسفة السياسـية، القـاهرة، دار الفجر ، ط) ع. أفلاطـون: الجمهوريـة، ترجمـة ودراســة د. فـؤاد زكريـا، الإسـكندرية، دار

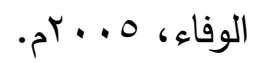
ه. إمـام عبد الفتاح إمـام: الطاغيـة (دراسـة فلسفية لصـور مـن الاسـتبداد)

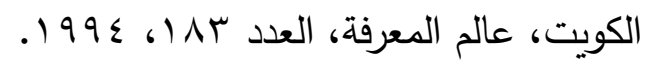
7 7. أميرة مطر : الفلسفة عند اليونان، القاهرة، دار الثقافة، طا. V. برتراند رسل: أثر العلم فى المجتمع، ترجمـة، تمام حسان، القاهرة، الهيئة

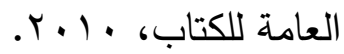

^. برتراند رسل: تاريخ الفلسفة الغربية، الكتاب الثالث، ترجمة، د. تحمد فتحي

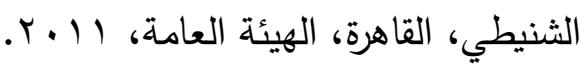

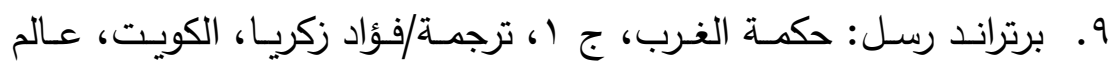

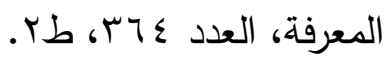
• 1. الجـاحظ: الحيـوان، تحقيـق، عبـد السـلام هـارون، بيـروت، دار الجيـل، 
Iا (.جورج سباين: تطور الفكر السياسي، الكتاب الأول، ترجمة: حسن جلال

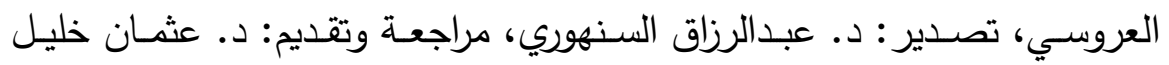
عثمان، القاهرة، دار المعارف، ؟90 19 1.

rا ب.جورج سباين: تطور الفكر السياسي، الكتاب الثالث، ترجمـة: د/راشــ

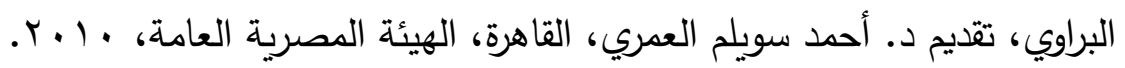

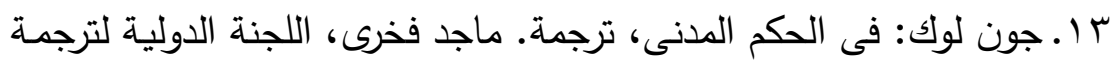

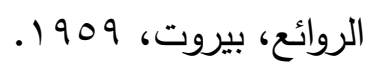

ـ ا ـ السيد عليوه وآخرون: مبادئ العلوم السياسية، القاهرة، دار طيبة. 1 1 . علاء حمروش: تاريخ الفلسفة السياسية، القاهرة، دار التعاون للطبع

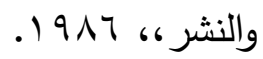

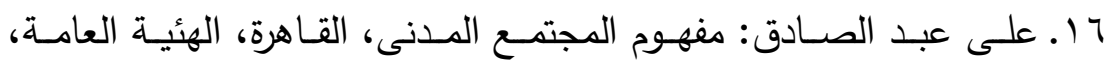

$$
. \text {. . . V }
$$

T V . . محمد فتحى الثنيطى: نماذج من الفلسفة السياسية، الاسكندرية، دار الوفاء،

$$
. r \cdot 17
$$

11 ا ـ هـوبز : اللفياثان، ترجمـة. دياناحبيب حرب، وبشـرى صـعب، مراجعـة

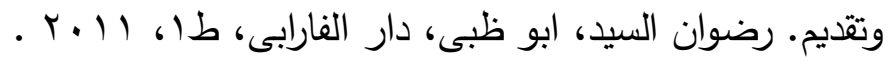

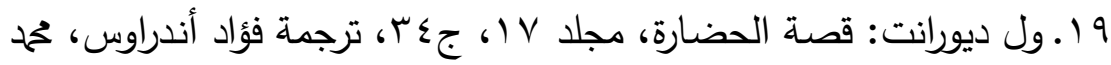

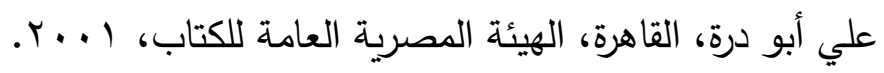

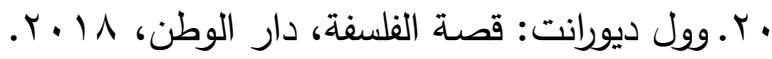

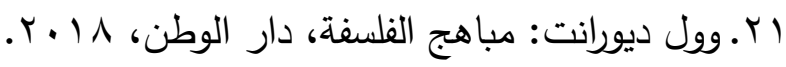

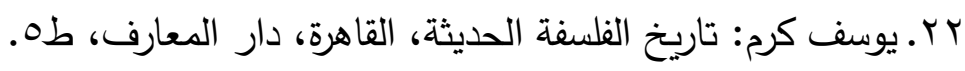

